\title{
Interleukin 4 gene polymorphism (-589C/T) and the risk of asthma: a meta-analysis and met-regression based on 55 studies
}

\author{
Ahmad Kousha', Armita Mahdavi Gorabi ${ }^{2}$, Mehdi Forouzesh ${ }^{3}$, Mojgan Hosseini ${ }^{4 *}$, Markov Alexander ${ }^{5}$, \\ Danyal Imani ${ }^{6}$, Bahman Razi ${ }^{7}$, Mohammad Javad Mousavi ${ }^{8,9}$, Saeed Aslani ${ }^{9}$ and Haleh Mikaeili ${ }^{10^{*}}$
}

\begin{abstract}
Background: Numerous investigations have previously evaluated the association of interleukin (IL) 4 gene polymorphisms and the risk of asthma, conferring inconsistent results. To resolve the incongruent outcomes yielded from different single studies, we conducted the most up-to-date meta-analysis of IL4 gene -589C/T (rs2243250) polymorphism and susceptibility to asthma.

Methods: A systematic literature search was performed in ISI web of science, Scopus, Medline/PubMed databases prior to September 2020, and the pooled odds ratio (OR) and their corresponding 95\% Cl were calculated to determine the association strength.

Results: Literature search led to retrieving of 49 publications (55 case-control studies) containing 9572 cases and 9881 controls. It was revealed that $I L 4$ gene $-589 \mathrm{C} / \mathrm{T}$ polymorphism increased the risk of asthma across all genetic models, including dominant model $(\mathrm{OR}=1.22)$, recessive model $(\mathrm{OR}=1.17)$, allelic model $(\mathrm{OR}=1.21)$, and $\Pi \mathrm{vs}$. $C C$ model $(\mathrm{OR}=1.34)$, but not the $C T$ vs. $\Pi T$ model. The subgroup analysis by age indicated that IL4 gene $-589 \mathrm{C} / T$ polymorphism was significantly associated with asthma risk in both pediatrics and adults. Additionally, the subgroup analysis by ethnicity revealed significant association in Asian, American, and Europeans. Finally, subgroup analysis by East Asian and non-East Asian populations indicated significant associations.
\end{abstract}

Conclusions: The current meta-analysis revealed that $1 / 4$ gene $-589 \mathrm{C} / \mathrm{T}$ polymorphism was a susceptibility risk in both pediatrics and adults in the whole and different ethnic groups.

Keywords: Asthma, Interleukin 4, Polymorphism, Meta-analysis, Genetic susceptibility

\section{Background}

Asthma is one of the most common atopic disorders of the respiratory tract, which results in wheezing, coughing, breathlessness, and bronchial obstruction [1]. The prevalence and incidence of asthma raised regularly and it estimated more than 300 million persons of the world

\footnotetext{
* Correspondence: mojgan-hosseini@iiau.ac.ir; mikaeilihale@gmail.com ${ }^{4}$ Department of Science, Islamshahr Branch, Islamic Azad University, Islamshahr, Tehran, Iran

${ }^{10}$ Tuberculosis and Lung Diseases Research Center, Tabriz University of Medical sciences, Tabriz, Iran

Full list of author information is available at the end of the article
}

are affected by this disease [2]. The main causes of asthma are not completely clear. However, is has been postulated that asthma is mediated by interactions between specific external stimulating factors, including pollutants, viral and bacterial infections, allergens, tobacco smokes, etc., and genetics of the patients. Additionally, increasing number of studies recommend that genetic factors play a critical role in the etiology of asthma by their interactions with the environmental elements [3, 4]. The heritability of asthma is estimated to be 35 to $95 \%$ [5]. Numerous studies have examined the

(C) The Author(s). 2021 Open Access This article is licensed under a Creative Commons Attribution 4.0 International License, which permits use, sharing, adaptation, distribution and reproduction in any medium or format, as long as you give appropriate credit to the original author(s) and the source, provide a link to the Creative Commons licence, and indicate if changes were made. The images or other third party material in this article are included in the article's Creative Commons licence, unless indicated otherwise in a credit line to the material. If material is not included in the article's Creative Commons licence and your intended use is not permitted by statutory regulation or exceeds the permitted use, you will need to obtain permission directly from the copyright holder. To view a copy of this licence, visit http://creativecommons.org/licenses/by/4.0/ The Creative Commons Public Domain Dedication waiver (http://creativecommons.org/publicdomain/zero/1.0/) applies to the data made available in this article, unless otherwise stated in a credit line to the data. 
correlation between genetic variations of pro and antiinflammatory genes and susceptibility to asthma $[6,7]$. In recent decades, single nucleotide polymorphisms (SNP) have become one of the frequently studied models of DNA variation in analyses of the association between genetics and susceptibility to disease $[8,9]$.

The role of immunological factors especially cytokines in modulating and controlling the inflammatory response of the respiratory tracts is essential in the evolution, progression, and exacerbations of asthma [10]. Interleukin (IL)-4 is a key ingredient of the immune system required in the regulation of response to an allergen through controlling the isotype switching of antibody in B lymphocytes to IgG and IgE class [11]. Elevated serum levels of IgE are suggestive of allergic reactions and resemble a high level of IL-4 mRNA assembly [12]. Moreover, it acts as a growth factor to facilitate the differentiation of $\mathrm{T}$ helper (Th) 2 cells and mast cells. These characteristics of IL- 4 accentuate on the crucial roles of cytokines in the pathogenesis asthma [13, 14]. Additionally, IL4 gene polymorphisms, like promoter region $(\mathrm{C}+33 \mathrm{~T}) \mathrm{SNP}$ [15], and $3017 \mathrm{G} / \mathrm{T}$ SNP in intron 2 [16], have been associated with IgE levels, which might be involved in the pathogenesis of asthma.

The IL4 gene is located on chromosome 5q31 [17]. The $-589 \mathrm{C} / \mathrm{T}$ (rs2243250) polymorphism has been recognized on upstream of the transcription initiation site [18]. It has been demonstrated that the binding of a transcription factor is enhanced by the appearance of the polymorphic $\mathrm{T}$ allele that may result in an overexpression of the IL4 gene and, thus, raising the power of any immunological response that dependents on IL-4 [19]. To date, many studies have examined the association between IL4 gene $-589 \mathrm{C} / \mathrm{T}$ polymorphisms and the risk of asthma, but their outcomes have not been consistent. Therefore, we performed this meta-analysis to analyze the relationship between the $-589 \mathrm{C} / \mathrm{T}$ polymorphisms and susceptibility to asthma.

\section{Methods}

This study conducted in accordance with the Preferred Reporting Items for Systematic reviews and Meta-Analyses (PRISMA) statement including; literature review, study selection, inclusion and exclusion criteria, data extraction and quality assessment, and statistical analysis [20]. No ethics committee confirmation was necessary for this meta-analysis, which does not contain any studies with human participants or animals performed by any of the authors.

\section{Literature review}

A comprehensive search was performed in the ISI web of science, Scopus, Medline/PubMed databases to retrieve published articles prior to September 2020. The following main key words and Medical Subject Headings (Mesh) were searched: ("asthma" [Mesh] OR "asthmatic") AND ("interleukin-4" OR "IL-4" OR "rs2243250") AND ("single nucleotide polymorphism" OR "SNP" OR "polymorphisms" OR "mutation" OR "variation"). No restrictions were placed on language, sample size, population or publication date.

\section{Study selection}

The retrieved publications by primary literature search were imported into Endnote X8 software. The duplicate studies were removed and title and abstract of remain studies were reviewed by two investigators. Full-text verification was performed if we could not categorize studies based on title and abstract. Any disagreements during study selection was discussed and resolved by consensus.

\section{Inclusion and exclusion criteria}

The following inclusion criteria were used to distinguish eligible studies: i) studies with distinct case and control group evaluating the association between IL-4 C589T polymorphism and susceptibility to asthma; ii) studies with calculable or extractable data for odds ratio (OR) and $95 \%$ confidence intervals (CIs); iii) studies with sufficient data for alleles and genotypes in case and control group. The duplicates, reviews, book chapters, and meta-analysis were excluded. The application of these criteria results in 49 qualified studies for the metaanalysis.

\section{Data extraction and quality assessment}

Two of our authors independently and according to an extraction checklist extracted the following data: the first author, journal and year of publication, country of origin, ethnicity, number of subjects in the case and the control groups for each gender, mean or range of age, genotyping method, genotype counts in the case and the control group. The quality of each study was assessed using the Newcastle-Ottawa Scale (NOS) criteria [21]. Studies with scores $0-3,4-6$ or 7-9 were low, moderate or high-quality, respectively.

\section{Statistical analysis}

Statistical analyses were carried out using STATA (version 14.0; Stata Corporation, College Station, TX) and SPSS (version 23.0; SPSS, Inc. Chicago, IL). The strength of association between polymorphism and asthma susceptibility was estimated by odd ratios (ORs) and 95\% confidence intervals (CIs) for the dominant model, recessive model, allele contrasts, and additive comparison. Heterogeneity among included studies was measured via $Q$ statistics $(P$ value $<0.1$ considered statistically significant) and $\mathrm{I}^{2}$-test $\left(\mathrm{I}^{2}\right.$ values of 25,50 and $75 \%$ were 
described as low, moderate, and high heterogeneity, respectively). In the presence of heterogeneity random effect model (REM) was used, however fixed effect model (FEM) was applied in homogeneous condition [22, 23]. In order to assessed the predefined sources of heterogeneity among included studies, subgroup analysis and meta-regression analysis based on year of population, the continent of the study population, and genotyping method were performed. The genotypic frequency distribution in the controls was checked for consistency of the Hardy- Weinberg equilibrium (HWE). Furthermore, publication bias was computed by the Begg's and Egger's test and visual examination of the funnel plot $(P$ value $<$ 0.05 considered statistically significant) [24, 25]. Additionally, to calculate overall effect size in absence of each study, a sensitivity analysis was conducted.

\section{Results}

\section{Search results and characteristics of the selected studies}

Our primary search retrieved 2121 potential articles. After removing of duplicate articles $(n=301), 1820$ articles remain for abstract and full-text screening. Of 1820 articles, 1612 were excluded base on title and abstract and 159 articles based on full-text reading. Ultimately 49 publications with 9579 cases and 9881 controls met the inclusion criteria and their data were extracted for meta-analysis. Among these 49 publications, four of them, including Basehore et al. [16], Donfack et al. [26], Zhang et al. [27], and Baye et al. [28] examined two or three different populations with separate case and control; therefore, we assumed them as 9 case-control studies collectively (55 studies). The detailed information on study selection process is illustrated in Fig. 1, Tables 1, and 2.

Meta-analysis of IL-4 SNP (C-589 T) and the risk of asthma Overall, 55 studies with 9572 cases and 9881 controls included in quantitative analysis of the association between IL-4 gene $-589 \mathrm{C} / \mathrm{T}$ polymorphism and the risk of asthma. Of those, 11 articles were conducted in European countries [29, 31, 33, 38-41, 55, 63, 64, 69], 32 articles were in Asian countries [27, 30, 32, 34-37, 43-46, $49,50,53,54,56-62,65,66,68,70-73], 10$ articles in American countries [16, 26, 28, 42, 48, 52] and one article in each Algeria [67] and Australia country [51]. The analysis of overall population revealed the significant positive association between $I L 4$ gene $-589 \mathrm{C} / \mathrm{T}$ polymorphism and the risk of asthma across all genetic models; including dominant model $(\mathrm{OR}=1.22,95 \% \mathrm{CI}=$ 1.04-1.44, $P=0.01$, REM), recessive model $(\mathrm{OR}=1.17$, 95\% $\mathrm{CI}=1.08-1.27, P<0.001$, FEM), allelic model (OR = 1.21, 95\% CI $=1.09-1.33, P<0.001, \mathrm{REM})$, and TT vs. CC model $(\mathrm{OR}=1.34,95 \% \mathrm{CI}=1.18-1.52, \quad P<0.001$, FEM), except CT vs. TT model $(\mathrm{OR}=1.13,95 \% \mathrm{CI}=$ 0.95-1.34, $P=0.17$, REM) (Fig. 2). Additionally, along with subgroup analysis based on age we stratified the analysis by ethnicity in three conditions.

\section{Subgroup analysis by age}

We stratified eligible articles into three groups including: pediatrics (16 articles), adults (21 articles) and mixed (cover both range;18 articles). The results highlighted a predisposing role of IL4 gene $-589 \mathrm{C} / \mathrm{T}$ polymorphism for the asthma risk in pediatrics and adults under all genotype models. However, no significant association was detected in mixed group (Table 3, Fig. 3).

\section{Subgroup analysis by ethnicity 1 (continent)}

In this subgroup we categorized studies by their continent: including Asia (32 articles), Europe (11 articles), America (10 articles), Africa (1 article), and Oceania (1 article). Since there was only one study for each one of the African and Australian population, these studies were excluded from the analysis. The results indicated that presence of IL4 gene -589C/T SNP in Asian population increased susceptibility of asthma across all genotype models except dominant model (OR $=1.15,95 \%$ $\mathrm{CI}=0.84-1.56, P=0.39, \mathrm{REM})$ and $\mathrm{CT}$ vs. $\mathrm{CC}$ model $(\mathrm{OR}=1,95 \% \mathrm{CI}=0.70-1.42, P=0.97, \mathrm{REM})$. Moreover, in contrast with effect of $I L 4$ gene $-589 \mathrm{C} / \mathrm{T}$ SNP on the risk of asthma in American populations, a significant positive association was detected in European population thorough dominant model $(\mathrm{OR}=1.46,95 \% \mathrm{CI}=1.15$ 1.85, $P<0.001$, REM $)$, allelic model $(\mathrm{OR}=1.34,95 \% \mathrm{CI}=$ $1.12-1.61, P<0.001$, REM), TT vs. $\mathrm{CC}$ model $(\mathrm{OR}=$ $1.53,95 \% \mathrm{CI}=1.10-2.14, P=0.01, \mathrm{FEM})$, and $\mathrm{CT}$ vs.CC model $(\mathrm{OR}=1.44,95 \% \mathrm{CI}=1.13-1.83, P<0.001$, REM $)$ (Table 3, Fig. 3).

\section{Subgroup analysis by ethnicity 2 (east and non-east Asian)}

The subgroup analysis according to East Asian (20 articles) and non-East Asian (35 articles) title revealed the significant association between IL4 gene $-589 \mathrm{C} / \mathrm{T}$ polymorphism and the risk of asthma across in all genotype models of East Asians and three genotype models of non-East Asian including; recessive model $(\mathrm{OR}=1.25,95 \% \mathrm{CI}=1.08-1.45$, $P<0.001$, FEM), allelic model ( $\mathrm{OR}=1.15,95 \% \mathrm{CI}=1-1.32$, $P=0.04, \mathrm{REM})$, TT vs. $\mathrm{CC}$ model $(\mathrm{OR}=1.34,95 \% \mathrm{CI}=$ 1.12-1.61, $P<0.001$, FEM) (Table 3, Fig. 4).

\section{Subgroup analysis by ethnicity 3}

Finally, subgroup analysis of eligible articles according ethnicity including Caucasians (41 articles), African-Americans (9 articles), and Arabs (5 articles) showed that there was no significant association between IL4 gene $-589 \mathrm{C} / \mathrm{T}$ SNP and asthma risk in Arab population. Also, except recessive model $(\mathrm{OR}=$ $1.18, \quad 95 \% \quad \mathrm{CI}=0.98-1.43, \quad P=0.07, \quad \mathrm{FEM}) \quad$ other 


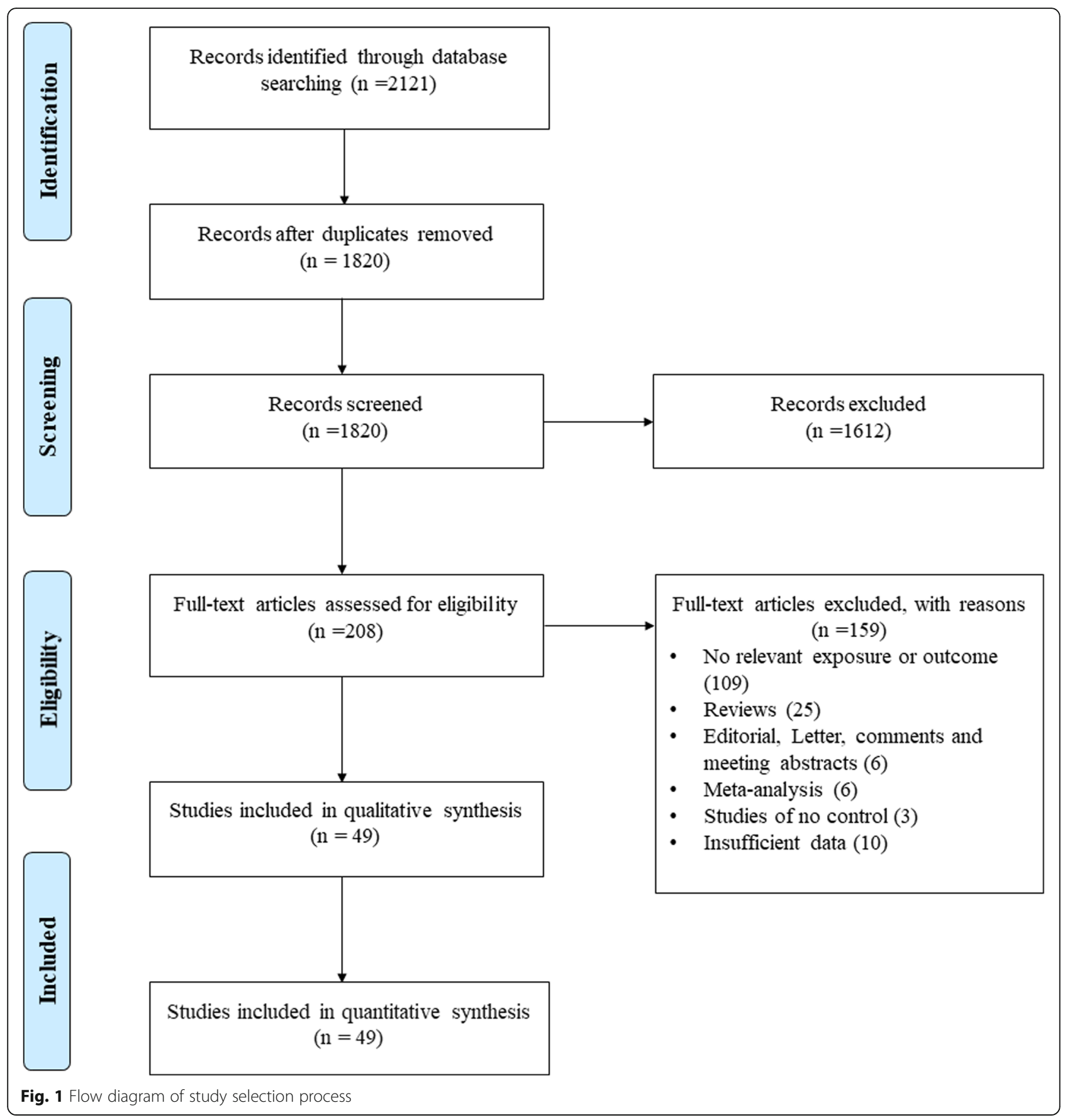

genotype models in African-American population were significant including dominant model $(\mathrm{OR}=$ $1.34, \quad 95 \% \quad \mathrm{CI}=1.07-1.67, \quad P=0.01, \quad$ FEM), allelic model $\quad(\mathrm{OR}=1.25, \quad 95 \% \quad \mathrm{CI}=1.04-1.50, \quad P=0.01$, REM), TT vs. CC model ( $\mathrm{OR}=1.37,95 \% \mathrm{CI}=1.04-$ $1.80, P=0.02$, FEM), and $\mathrm{CT}$ vs. $\mathrm{CC}$ model $(\mathrm{OR}=$ 1.30, 95\% CI $=1.06-1.58, P=0.01$, FEM). Conversely, all genotype models were significant in Caucasians and presence of $I L 4$ gene $-589 \mathrm{C} / \mathrm{T}$ SNP increase risk of asthma (Table 3, Fig. 4).

\section{Meta-regression analyses}

Meta-regression analyses were performed to explore potential sources of heterogeneity among included studies (Table 4). The findings indicated that none of the expected heterogeneity parameter were the source of heterogeneity (Fig. 5).

\section{Publication bias}

To check existence of publication, Egger's linear regression and Begg's funnel plot test were used. The shape of 
Table 1 Characteristics of studies included in meta-analysis of overall asthma

\begin{tabular}{|c|c|c|c|c|c|c|c|c|c|}
\hline Study author & Year & Country & $\begin{array}{l}\text { Ethnicity } 1 \\
\text { (Continent) }\end{array}$ & $\begin{array}{l}\text { Ethnicity } \\
2\end{array}$ & Ethnicity 3 & $\begin{array}{l}\text { Age } \\
\text { group }\end{array}$ & $\begin{array}{l}\text { Total cases/ } \\
\text { control }\end{array}$ & Genotyping method & $\begin{array}{l}\text { Quality } \\
\text { Score }\end{array}$ \\
\hline Walley et al. [29] & 1996 & UK & Europe & $\begin{array}{l}\text { non East- } \\
\text { Asian }\end{array}$ & Caucasian & Pediatric & $124 / 59$ & PCR-RFLP & 6 \\
\hline Hijazi et al. [30] & 2000 & Kuwait & Asia & $\begin{array}{l}\text { non East- } \\
\text { Asian }\end{array}$ & Arab & Mixed & $84 / 100$ & PCR-RFLP & 6 \\
\hline Sandford et al. [31] & 2000 & $\begin{array}{l}\text { New } \\
\text { Zealand }\end{array}$ & Europe & $\begin{array}{l}\text { non East- } \\
\text { Asian }\end{array}$ & Caucasian & Adult & $233 / 143$ & PCR-RFLP & 7 \\
\hline Takabayashi et al. [32] & 2000 & Japan & Asia & East-Asian & Caucasian & Pediatric & $100 / 100$ & PCR-RFLP & 6 \\
\hline Hakonarson et al. [33] & 2001 & Iceland & Europe & $\begin{array}{l}\text { non East- } \\
\text { Asian }\end{array}$ & Caucasian & Mixed & $94 / 94$ & PCR & 6 \\
\hline Cui et al. [34] & 2003 & China & Asia & East-Asian & Caucasian & Mixed & $241 / 175$ & PCR-RFLP & 7 \\
\hline Basehore et al. (i) [16] & 2004 & USA & America & $\begin{array}{l}\text { non East- } \\
\text { Asian }\end{array}$ & $\begin{array}{l}\text { African } \\
\text { American }\end{array}$ & Adult & $233 / 245$ & PCR & 7 \\
\hline Basehore et al. (ii) [16] & 2004 & USA & America & $\begin{array}{l}\text { non East- } \\
\text { Asian }\end{array}$ & $\begin{array}{l}\text { African } \\
\text { American }\end{array}$ & Adult & $168 / 269$ & PCR & 7 \\
\hline $\begin{array}{l}\text { Basehore et al. (iii) } \\
\text { [16] }\end{array}$ & 2004 & USA & America & $\begin{array}{l}\text { non East- } \\
\text { Asian }\end{array}$ & $\begin{array}{l}\text { African } \\
\text { American }\end{array}$ & Adult & $116 / 130$ & PCR & 6 \\
\hline Lee et al. [35] & 2004 & Korea & Asia & East-Asian & Caucasian & Pediatric & $254 / 100$ & PCR-RFLP & 6 \\
\hline Park et al. [36] & 2004 & Korea & Asia & East-Asian & Caucasian & Mixed & $532 / 170$ & SNaPshot & 8 \\
\hline Wang et al. [37] & 2004 & China & Asia & East-Asian & Caucasian & Adult & $93 / 62$ & PCR-RFLP & 6 \\
\hline Adjers et al. [38] & 2004 & Finland & Europe & $\begin{array}{l}\text { non East- } \\
\text { Asian }\end{array}$ & Caucasian & Adult & $243 / 401$ & PCR-RFLP & 7 \\
\hline Donfack et al. (i) [26] & 2005 & USA & America & $\begin{array}{l}\text { non East- } \\
\text { Asian }\end{array}$ & $\begin{array}{l}\text { African } \\
\text { American }\end{array}$ & Mixed & $126 / 205$ & LAS & 6 \\
\hline Donfack et al. (ii) [26] & 2005 & USA & America & $\begin{array}{l}\text { non East- } \\
\text { Asian }\end{array}$ & $\begin{array}{l}\text { African } \\
\text { American }\end{array}$ & Mixed & $205 / 183$ & LAS & 7 \\
\hline Zhang et al. (i) [27] & 2005 & China & Asia & East-Asian & Caucasian & Adult & $152 / 157$ & PCR-RFLP & 6 \\
\hline Zhang et al. (ii) [27] & 2005 & Malaysia & Asia & East-Asian & Caucasian & Adult & $76 / 100$ & PCR-RFLP & 6 \\
\hline Zhang et al. (iii) [27] & 2005 & India & Asia & $\begin{array}{l}\text { non East- } \\
\text { Asian }\end{array}$ & Caucasian & Adult & $87 / 103$ & PCR-RFLP & 6 \\
\hline Gervaziev et al. [39] & 2006 & Russia & Europe & $\begin{array}{l}\text { non East- } \\
\text { Asian }\end{array}$ & Caucasian & Adult & $109 / 68$ & PCR-RFLP & 6 \\
\hline Schubert et al. [40] & 2006 & Germany & Europe & $\begin{array}{l}\text { non East- } \\
\text { Asian }\end{array}$ & Caucasian & Pediatric & $231 / 270$ & PCR-RFLP & 7 \\
\hline Kabesch et al. [41] & 2006 & Germany & Europe & $\begin{array}{l}\text { non East- } \\
\text { Asian }\end{array}$ & Caucasian & Pediatric & $73 / 773$ & PCR-RFLP & 6 \\
\hline Battle et al. [42] & 2007 & USA & America & $\begin{array}{l}\text { non East- } \\
\text { Asian }\end{array}$ & $\begin{array}{l}\text { African } \\
\text { American }\end{array}$ & Mixed & $255 / 175$ & PCR-RFLP & 6 \\
\hline $\begin{array}{l}\text { Hosseini-Farahabadi } \\
\text { et al. [43] }\end{array}$ & 2007 & Iran & Asia & $\begin{array}{l}\text { non East- } \\
\text { Asian }\end{array}$ & Caucasian & Adult & $30 / 50$ & PCR-RFLP & 5 \\
\hline $\begin{array}{l}\text { Kamali-Sarvestani et } \\
\text { al. [44] }\end{array}$ & 2007 & Iran & Asia & $\begin{array}{l}\text { non East- } \\
\text { Asian }\end{array}$ & Caucasian & Adult & $149 / 112$ & PCR-RFLP & 6 \\
\hline Chiang et al. [45] & 2007 & China & Asia & East-Asian & Caucasian & Adult & $167 / 111$ & PCR-RFLP & 6 \\
\hline Mak et al. [46] & 2007 & China & Asia & East-Asian & Caucasian & Adult & $289 / 292$ & PCR-RFLP & 7 \\
\hline Attab et al. [47] & 2008 & Jordan & Asia & $\begin{array}{l}\text { non East- } \\
\text { Asian }\end{array}$ & Arab & Pediatric & $40 / 40$ & PCR-RFLP & 5 \\
\hline De Faria et al. [48] & 2008 & Brazil & America & $\begin{array}{l}\text { non East- } \\
\text { Asian }\end{array}$ & Caucasian & Pediatric & $88 / 202$ & PCR-RFLP & 6 \\
\hline Jiang et al. [49] & 2009 & China & Asia & East-Asian & Caucasian & Adult & $13 / 13$ & PCR-RFLP & 5 \\
\hline Amirzargar et al. [50] & 2009 & Iran & Asia & $\begin{array}{l}\text { non East- } \\
\text { Asian }\end{array}$ & Caucasian & Mixed & $59 / 139$ & PCR-RFLP & 6 \\
\hline Daley et al. [51] & 2009 & Australia & Oceania & $\begin{array}{l}\text { non East- } \\
\text { Asian }\end{array}$ & Caucasian & Mixed & $644 / 751$ & $\begin{array}{l}\text { Illumina Bead array } \\
\text { system }\end{array}$ & 8 \\
\hline
\end{tabular}


Table 1 Characteristics of studies included in meta-analysis of overall asthma (Continued)

\begin{tabular}{|c|c|c|c|c|c|c|c|c|c|}
\hline Study author & Year & Country & $\begin{array}{l}\text { Ethnicity } 1 \\
\text { (Continent) }\end{array}$ & $\begin{array}{l}\text { Ethnicity } \\
2\end{array}$ & Ethnicity 3 & $\begin{array}{l}\text { Age } \\
\text { group }\end{array}$ & $\begin{array}{l}\text { Total cases/ } \\
\text { control }\end{array}$ & Genotyping method & $\begin{array}{l}\text { Quality } \\
\text { Score }\end{array}$ \\
\hline Haller et al. [52] & 2009 & USA & America & $\begin{array}{l}\text { non East- } \\
\text { Asian }\end{array}$ & $\begin{array}{l}\text { African } \\
\text { American }\end{array}$ & Adult & $72 / 70$ & PCR-RFLP & 6 \\
\hline Rad et al. [53] & 2010 & Iran & Asia & $\begin{array}{l}\text { non East- } \\
\text { Asian }\end{array}$ & Caucasian & Adult & $64 / 65$ & PCR-RFLP & 6 \\
\hline Wu et al. [54] & 2010 & China & Asia & East-Asian & Caucasian & Pediatric & $252 / 227$ & PCR-RFLP & 7 \\
\hline Beghe et al. [55] & 2010 & $\begin{array}{l}\text { UK and } \\
\text { Italy }\end{array}$ & Europe & $\begin{array}{l}\text { non East- } \\
\text { Asian }\end{array}$ & Caucasian & Mixed & $299 / 176$ & PCR-RFLP & 7 \\
\hline Bijanzadeh et al. [56] & 2010 & India & Asia & $\begin{array}{l}\text { non East- } \\
\text { Asian }\end{array}$ & Caucasian & Mixed & $100 / 50$ & PCR-RFLP & 6 \\
\hline Fance et al. [57] & 2010 & China & Asia & East-Asian & Caucasian & Adult & $62 / 30$ & PCR-RFLP & 6 \\
\hline Baye et al. (i) [28] & 2011 & USA & America & $\begin{array}{l}\text { non East- } \\
\text { Asian }\end{array}$ & $\begin{array}{l}\text { African } \\
\text { American }\end{array}$ & Pediatric & $413 / 298$ & $\begin{array}{l}\text { Illumina GoldenGate } \\
\text { Assay system }\end{array}$ & 7 \\
\hline Baye et al. (ii) [28] & 2011 & USA & America & $\begin{array}{l}\text { non East- } \\
\text { Asian }\end{array}$ & $\begin{array}{l}\text { African } \\
\text { American }\end{array}$ & Pediatric & $315 / 51$ & $\begin{array}{l}\text { Illumina GoldenGate } \\
\text { Assay system }\end{array}$ & 6 \\
\hline $\begin{array}{l}\text { Daneshmandi et al. } \\
\text { [58] }\end{array}$ & 2011 & Iran & Asia & $\begin{array}{l}\text { non East- } \\
\text { Asian }\end{array}$ & Caucasian & Adult & $81 / 124$ & PCR-RFLP & 7 \\
\hline Huang et al. [59] & 2011 & China & Asia & East-Asian & Caucasian & Pediatric & $100 / 122$ & PCR-RFLP & 6 \\
\hline Hwang et al. [60] & 2012 & China & Asia & East-Asian & Caucasian & Pediatric & $188 / 376$ & PCR-RFLP & 7 \\
\hline Chiang et al. [61] & 2012 & China & Asia & East-Asian & Caucasian & Adult & $452 / 106$ & PCR-RFLP & 6 \\
\hline Micheal et al. [62] & 2013 & Pakistan & Asia & $\begin{array}{l}\text { non East- } \\
\text { Asian }\end{array}$ & Caucasian & Mixed & $108 / 120$ & PCR-RFLP & 6 \\
\hline Ricciardolo et al. [63] & 2013 & Italy & Europe & $\begin{array}{l}\text { non East- } \\
\text { Asian }\end{array}$ & Caucasian & Mixed & $57 / 124$ & PCR-SSP & 6 \\
\hline Smolnikova et al. [64] & 2013 & Russia & Europe & $\begin{array}{l}\text { non East- } \\
\text { Asian }\end{array}$ & Caucasian & Mixed & $64 / 50$ & PCR-RFLP & 6 \\
\hline Li et al. [65] & 2014 & China & Asia & East-Asian & Caucasian & Pediatric & $491 / 503$ & PCR-LDR & 7 \\
\hline Wang et al. [66] & 2015 & China & Asia & East-Asian & Caucasian & Mixed & $392 / 849$ & Mass array & 7 \\
\hline Dahmani et al. [67] & 2016 & Algeria & Africa & $\begin{array}{l}\text { non East- } \\
\text { Asian }\end{array}$ & Arab & Adult & $44 / 19$ & PCR-RFLP & 6 \\
\hline Li et al. [68] & 2016 & China & Asia & East-Asian & Caucasian & Pediatric & $317 / 351$ & PCR and Sequencing & 7 \\
\hline Narozna et al. [69] & 2016 & Poland & Europe & $\begin{array}{l}\text { non East- } \\
\text { Asian }\end{array}$ & Caucasian & Mixed & $177 / 189$ & Taq Man & 7 \\
\hline Zhang et al. [68] & 2016 & China & Asia & East-Asian & Caucasian & Pediatric & $38 / 35$ & PCR and Sequencing & 6 \\
\hline Hussein et al. [70] & 2017 & Iraq & Asia & $\begin{array}{l}\text { non East- } \\
\text { Asian }\end{array}$ & Arab & Mixed & $48 / 25$ & ARMS-PCR & 6 \\
\hline Abood et al. [71] & 2018 & Iraq & Asia & $\begin{array}{l}\text { non East- } \\
\text { Asian }\end{array}$ & Arab & Mixed & $100 / 100$ & AS-PCR & 6 \\
\hline Zhang et al. [72] & 2019 & China & Asia & East-Asian & Caucasian & Pediatric & $37 / 29$ & PCR and Sequencing & 5 \\
\hline
\end{tabular}

funnel plot did not disclose obvious asymmetry under all genotype model of the IL4 gene $-589 \mathrm{C} / \mathrm{T}$ polymorphism (Fig. 6).

\section{Sensitivity analysis}

The impact of individual study on pooled OR was evaluated by sequential omission of each studies. The result showed that no individual study significantly affected the pooled ORs under all genotype models of the IL4 gene -589 C/T polymorphism (Fig. 7).

\section{Discussion}

To date, several individual case-control replication studies have attempted to divulge the association of IL4 gene $-589 \mathrm{C} / \mathrm{T}$ polymorphism and risk of asthma. Due to some differences, however, these disperse investigation demonstrated incongruous reports. The differences in the race of study subjects, diversity in the diagnostic criteria of the patients, limited sample sizes may be the cause of such inconsistent results [74]. On the other hand, meta-analysis is a tool that has the potential to solve the problem of 
Table 2 Distribution of genotype and allele among asthma patients and controls

\begin{tabular}{|c|c|c|c|c|c|c|c|c|c|c|c|c|}
\hline \multirow[t]{2}{*}{ Study author } & \multicolumn{5}{|c|}{ Asthma cases } & \multicolumn{5}{|c|}{ Healthy control } & \multirow{2}{*}{$\begin{array}{l}\text { P- } \\
\text { HWE }\end{array}$} & \multirow[t]{2}{*}{ MAF } \\
\hline & $\mathrm{CC}$ & CT & $\mathrm{TT}$ & $\mathrm{C}$ & $T$ & CC & CT & $\mathrm{TT}$ & $\mathrm{C}$ & $\mathbf{T}$ & & \\
\hline Walley et al. [29] & 56 & 55 & 13 & 167 & 81 & 31 & 23 & 5 & 85 & 33 & $0 / 8$ & $0 / 72$ \\
\hline Hijazi et al. [30] & 5 & 25 & 54 & 35 & 133 & 9 & 31 & 60 & 49 & 151 & $0 / 1$ & $0 / 245$ \\
\hline Sandford et al. [31] & 146 & 78 & 9 & 370 & 96 & 100 & 41 & 2 & 241 & 45 & $0 / 33$ & $0 / 842$ \\
\hline Takabayashi et al. [32] & 6 & 43 & 51 & 55 & 145 & 10 & 39 & 51 & 59 & 141 & $0 / 53$ & $0 / 295$ \\
\hline Hakonarson et al. [33] & 73 & 20 & 1 & 166 & 22 & 67 & 25 & 2 & 159 & 29 & $0 / 85$ & $0 / 845$ \\
\hline Cui et al. [34] & 11 & 89 & 141 & 111 & 371 & 9 & 52 & 114 & 70 & 280 & $0 / 34$ & $0 / 2$ \\
\hline Basehore et al. (i) [16] & 153 & 72 & 8 & 378 & 88 & 181 & 59 & 5 & 421 & 69 & 0/94 & $0 / 859$ \\
\hline Basehore et al. (ii) [16] & 22 & 77 & 69 & 121 & 215 & 29 & 119 & 121 & 177 & 361 & 0/97 & $0 / 329$ \\
\hline Basehore et al. (iii) [16] & 43 & 55 & 18 & 141 & 91 & 55 & 59 & 16 & 169 & 91 & $0 / 97$ & $0 / 65$ \\
\hline Lee et al. [35] & 9 & 77 & 168 & 95 & 413 & 3 & 29 & 68 & 35 & 165 & $0 / 96$ & $0 / 175$ \\
\hline Park et al. [36] & 19 & 164 & 349 & 202 & 862 & 7 & 54 & 109 & 68 & 272 & $0 / 92$ & $0 / 2$ \\
\hline Wang et al. [37] & 29 & 42 & 22 & 100 & 86 & 21 & 26 & 15 & 68 & 56 & $0 / 22$ & $0 / 548$ \\
\hline Adjers et al. [38] & 106 & 103 & 34 & 315 & 171 & 189 & 164 & 48 & 542 & 260 & $0 / 18$ & $0 / 675$ \\
\hline Donfack et al. (i) [26] & 85 & 34 & 7 & 204 & 48 & 144 & 55 & 6 & 343 & 67 & $0 / 78$ & $0 / 836$ \\
\hline Donfack et al. (ii) [26] & 25 & 82 & 98 & 132 & 278 & 24 & 82 & 77 & 130 & 236 & $0 / 76$ & $0 / 355$ \\
\hline Zhang et al. (i) [27] & 4 & 47 & 101 & 55 & 249 & 3 & 45 & 109 & 51 & 263 & $0 / 5$ & $0 / 162$ \\
\hline Zhang et al. (ii) [27] & 11 & 35 & 30 & 57 & 95 & 16 & 43 & 41 & 75 & 125 & $0 / 4$ & $0 / 375$ \\
\hline Zhang et al. (iii) [27] & 50 & 31 & 6 & 131 & 43 & 66 & 30 & 7 & 162 & 44 & $0 / 17$ & 0/786 \\
\hline Gervaziev et al. [39] & 16 & 75 & 18 & 107 & 111 & 18 & 43 & 7 & 79 & 57 & $0 / 01$ & $0 / 58$ \\
\hline Schubert et al. [40] & 143 & 78 & 10 & 364 & 98 & 189 & 74 & 7 & 452 & 88 & $0 / 93$ & $0 / 837$ \\
\hline Kabesch et al. [41] & 42 & 29 & 2 & 113 & 33 & 564 & 188 & 21 & 1316 & 230 & $0 / 26$ & $0 / 851$ \\
\hline Battle et al. [42] & 28 & 113 & 114 & 169 & 341 & 19 & 77 & 79 & 115 & 235 & $0 / 97$ & $0 / 328$ \\
\hline Hosseini-Farahabadi et al. [43] & 17 & 8 & 5 & 42 & 18 & 38 & 12 & 0 & 88 & 12 & $0 / 33$ & $0 / 88$ \\
\hline Kamali-Sarvestani et al. [44] & 139 & 6 & 4 & 284 & 14 & 93 & 18 & 1 & 204 & 20 & $0 / 9$ & $0 / 91$ \\
\hline Chiang et al. [45] & 1 & 19 & 147 & 21 & 313 & 7 & 34 & 70 & 48 & 174 & $0 / 31$ & $0 / 216$ \\
\hline Mak et al. [46] & 15 & 95 & 179 & 125 & 453 & 19 & 87 & 186 & 125 & 459 & $0 / 05$ & $0 / 214$ \\
\hline Attab et al. [47] & 31 & 9 & 0 & 71 & 9 & 33 & 7 & 0 & 73 & 7 & $0 / 54$ & 0/912 \\
\hline De Faria et al. [48] & 38 & 41 & 9 & 117 & 59 & 67 & 108 & 27 & 242 & 162 & $0 / 1$ & 0/599 \\
\hline Jiang et al. [49] & 0 & 8 & 5 & 8 & 18 & 1 & 9 & 3 & 11 & 15 & $0 / 13$ & $0 / 423$ \\
\hline Amirzargar et al. [50] & 0 & 59 & 0 & 59 & 59 & 10 & 129 & 0 & 149 & 129 & $<0.001$ & $0 / 535$ \\
\hline Daley et al. [51] & 476 & 155 & 13 & 1107 & 181 & 549 & 186 & 16 & 1284 & 218 & $0 / 95$ & $0 / 854$ \\
\hline Haller et al. [52] & 6 & 30 & 36 & 42 & 102 & 7 & 31 & 32 & 45 & 95 & $0 / 89$ & $0 / 321$ \\
\hline Rad et al. [53] & 46 & 18 & 0 & 110 & 18 & 42 & 23 & 0 & 107 & 23 & $0 / 08$ & $0 / 823$ \\
\hline Wu et al. [54] & 6 & 83 & 163 & 95 & 409 & 11 & 84 & 132 & 106 & 348 & $0 / 61$ & $0 / 233$ \\
\hline Beghe et al. [55] & 232 & 63 & 4 & 527 & 71 & 136 & 37 & 3 & 309 & 43 & $0 / 79$ & $0 / 877$ \\
\hline Bijanzadeh et al. [56] & 92 & 4 & 4 & 188 & 12 & 48 & 1 & 1 & 97 & 3 & $<0.001$ & $0 / 97$ \\
\hline Fance et al. [57] & 38 & 13 & 11 & 89 & 35 & 27 & 1 & 2 & 55 & 5 & $<0.001$ & 0/916 \\
\hline Baye et al. (i) [28] & 267 & 130 & 16 & 664 & 162 & 233 & 61 & 4 & 527 & 69 & $0 / 99$ & $0 / 884$ \\
\hline Baye et al. (ii) [28] & 35 & 140 & 140 & 210 & 420 & 12 & 25 & 14 & 49 & 53 & $0 / 89$ & $0 / 48$ \\
\hline Daneshmandi et al. [58] & 63 & 15 & 3 & 141 & 21 & 94 & 26 & 4 & 214 & 34 & $0 / 2$ & $0 / 862$ \\
\hline Huang et al. [59] & 1 & 19 & 80 & 21 & 179 & 4 & 43 & 75 & 51 & 193 & $0 / 46$ & 0/209 \\
\hline Hwang et al. [60] & 1 & 51 & 136 & 53 & 323 & 12 & 89 & 275 & 113 & 639 & $0 / 15$ & $0 / 15$ \\
\hline Chiang et al. [61] & 13 & 110 & 329 & 136 & 768 & 7 & 34 & 65 & 48 & 164 & $0 / 38$ & $0 / 226$ \\
\hline
\end{tabular}


Table 2 Distribution of genotype and allele among asthma patients and controls (Continued)

\begin{tabular}{|c|c|c|c|c|c|c|c|c|c|c|c|c|}
\hline \multirow[t]{2}{*}{ Study author } & \multicolumn{5}{|c|}{ Asthma cases } & \multicolumn{5}{|c|}{ Healthy control } & \multirow{2}{*}{$\begin{array}{l}\text { P- } \\
\text { HWE }\end{array}$} & \multirow[t]{2}{*}{ MAF } \\
\hline & CC & CT & $\mathrm{TT}$ & C & $T$ & CC & $\mathrm{CT}$ & $\mathrm{TT}$ & $\mathrm{C}$ & $\mathbf{T}$ & & \\
\hline Micheal et al. [62] & 26 & 63 & 19 & 115 & 101 & 31 & 84 & 5 & 146 & 94 & $<0.001$ & $0 / 608$ \\
\hline Ricciardolo et al. [63] & 35 & 19 & 3 & 89 & 25 & 109 & 12 & 3 & 230 & 18 & $<0.001$ & 0/927 \\
\hline Smolnikova et al. [64] & 36 & 28 & 0 & 100 & 28 & 39 & 11 & 0 & 89 & 11 & $0 / 38$ & $0 / 89$ \\
\hline Li et al. [65] & 17 & 150 & 324 & 184 & 798 & 21 & 144 & 338 & 186 & 820 & $0 / 26$ & $0 / 184$ \\
\hline Wang et al. [66] & 50 & 177 & 165 & 277 & 507 & 104 & 412 & 333 & 620 & 1078 & $0 / 17$ & $0 / 365$ \\
\hline Dahmani et al. [67] & 13 & 19 & 12 & 45 & 43 & 6 & 11 & 2 & 23 & 15 & $0 / 35$ & $0 / 605$ \\
\hline Li et al. [68] & 112 & 0 & 205 & 224 & 410 & 138 & 0 & 213 & 276 & 426 & $<0.001$ & 0/393 \\
\hline Narozna et al. [69] & 117 & 55 & 5 & 289 & 65 & 133 & 53 & 3 & 319 & 59 & $0 / 37$ & $0 / 843$ \\
\hline Zhang et al. [68] & 8 & 11 & 19 & 27 & 49 & 17 & 13 & 5 & 47 & 23 & $0 / 34$ & $0 / 671$ \\
\hline Hussein et al. [70] & 42 & 5 & 1 & 89 & 7 & 8 & 13 & 4 & 29 & 21 & $0 / 73$ & $0 / 58$ \\
\hline Abood et al. [71] & 66 & 17 & 17 & 149 & 51 & 7 & 90 & 3 & 104 & 96 & $<0.001$ & $0 / 52$ \\
\hline Zhang et al. [72] & 7 & 13 & 17 & 27 & 47 & 11 & 15 & 3 & 37 & 21 & $0 / 51$ & $0 / 637$ \\
\hline
\end{tabular}

$P$-HWE $p$-value for Hardy-Weinberg equilibrium, MAF minor allele frequency of control group

inconsistency by removing the confining issues of insufficient statistical power in the individual studies. Therefore, to resolve the mentioned confining factors about the IL4 gene $-589 \mathrm{C} / \mathrm{T}$ polymorphism, the present most up-to-date meta-analysis was conducted to determine a bona fide estimation of the association between IL4 gene -589C/T polymorphism and susceptibility to asthma. Our analysis indicated that this
SNP was associated with increased risk of asthma in the overall population as well as during subgroup analysis by age groups and ethnicity/continent.

Asthma is a complicated pulmonary disease, characterized by airway hyperresponsiveness, airway inflammation, and airway remodeling [75, 76]. During asthma, there is a hyperactivity of Th2 responses, in which the cytokines of the type 2 immunity, such as IL-4, IL-5, and

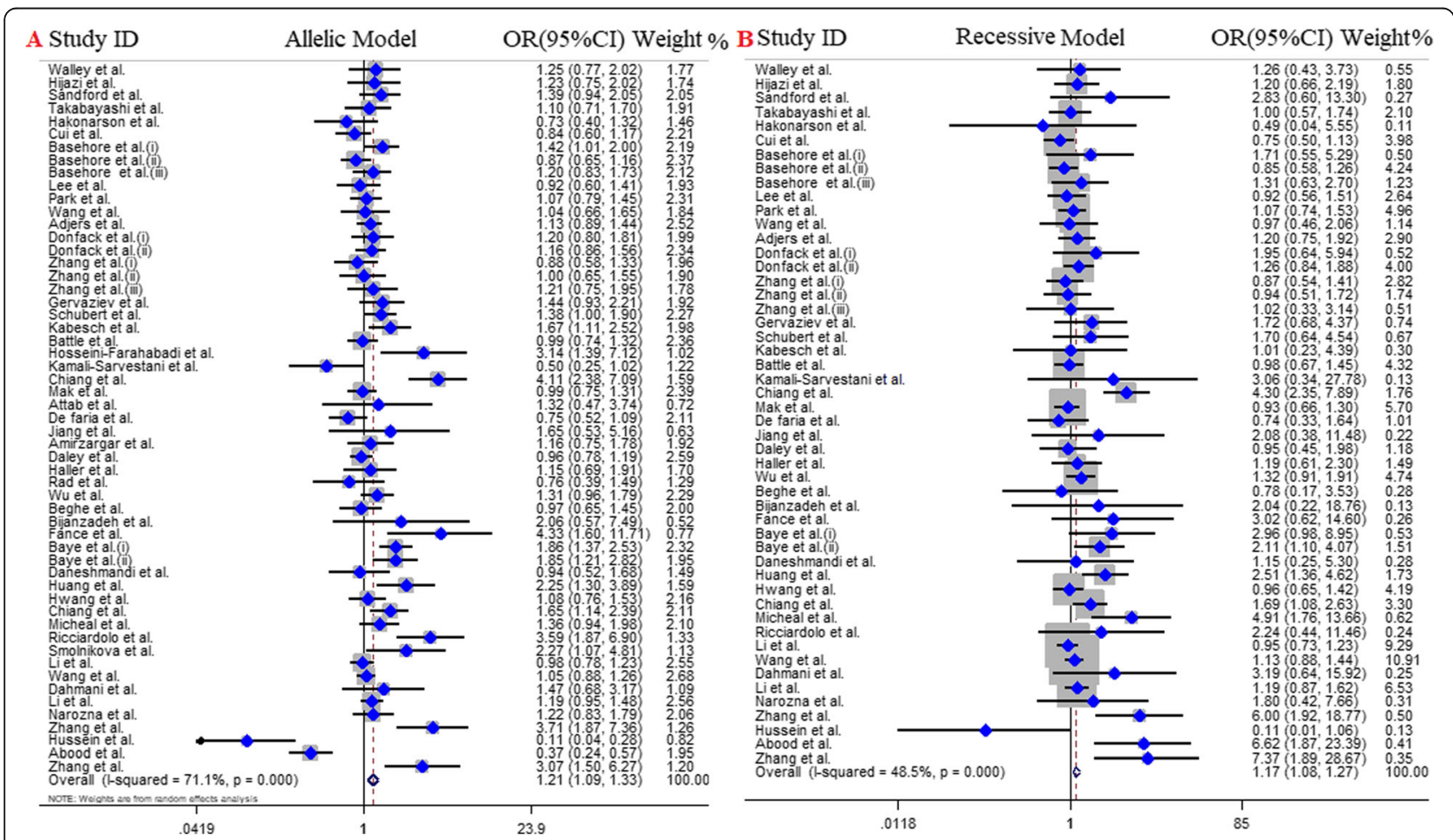

Fig. 2 Pooled OR and 95\% Cl of individual studies and pooled data for the association between II-4 C589T polymorphism and asthma risk in; a allelic model, $\mathbf{b}$ recessive Model 
Table 3 Main results of pooled ORs in meta-analysis of IL-4 gene polymorphisms in asthmatic patients

\begin{tabular}{|c|c|c|c|c|c|c|c|c|c|c|}
\hline \multirow[t]{2}{*}{ Subgroup } & \multirow[b]{2}{*}{ Genetic model } & \multirow{2}{*}{$\begin{array}{l}\text { Sample size } \\
\text { Case/Control }\end{array}$} & \multicolumn{2}{|c|}{ Test of association } & \multicolumn{2}{|c|}{$\begin{array}{l}\text { Test of } \\
\text { heterogeneity }\end{array}$} & \multicolumn{2}{|c|}{$\begin{array}{l}\text { Test of publication } \\
\text { bias (Begg's test) }\end{array}$} & \multicolumn{2}{|c|}{$\begin{array}{l}\text { Test of publication } \\
\text { bias (Egger's test) }\end{array}$} \\
\hline & & & $\overline{\mathrm{OR}}$ & $95 \% \mathrm{Cl}$ ( $p$-value) & $\mathrm{I}^{2}(\%)$ & $P$ & $z$ & $P$ & $t$ & $P$ \\
\hline \multirow[t]{5}{*}{ Overall } & Dominant model & $9579 / 9881$ & 1.22 & $1.04-1.44(0.01)$ & 69.7 & $<0.001$ & -1.33 & 0.24 & -1.17 & 0.39 \\
\hline & Recessive model & 9579 / 9881 & 1.17 & $1.08-1.27(<0.001)$ & 48.5 & $<0.001$ & -1.38 & 0.16 & -0.60 & 0.55 \\
\hline & Allelic model & $9579 / 9881$ & 1.21 & $1.09-1.33(<0.001)$ & 71.1 & $<0.001$ & -1.05 & 0.41 & -1.82 & 0.07 \\
\hline & TT vs. CC & $9579 / 9881$ & 1.34 & $1.18-1.52(<0.001)$ & 30.5 & 0.02 & -1.25 & 0.24 & -1.90 & 0.65 \\
\hline & CT vs. CC & 9579 / 9881 & 1.13 & $0.95-1.34(0.17)$ & 68.7 & $<0.001$ & -2.06 & 0.33 & -1.73 & 0.09 \\
\hline \multicolumn{11}{|l|}{ Age groups } \\
\hline \multirow[t]{5}{*}{ Pediatrics } & Dominant model & $3061 / 3536$ & 1.54 & $1.24-1.92(<0.001)$ & 41 & 0.04 & -1.93 & 0.05 & -1.63 & 0.23 \\
\hline & Recessive model & $3061 / 3536$ & 1.20 & $1.05-1.37(<0.001)$ & 58.3 & $<0.001$ & -0.36 & 0.71 & -1.14 & 0.27 \\
\hline & Allelic model & $3061 / 3536$ & 1.37 & $1.16-1.63(<0.001)$ & 68 & $<0.001$ & -1.53 & 0.12 & -1.99 & 0.06 \\
\hline & TT vs. CC & $3061 / 3536$ & 1.51 & $1.22-1.87(<0.001)$ & 51.6 & 0.01 & -1.44 & 0.15 & -1.47 & 0.24 \\
\hline & CT vs. CC & $3061 / 3536$ & 1.49 & $1.23-1.81(<0.001)$ & 10.6 & 0.33 & -1.92 & 0.05 & -1.22 & 0.42 \\
\hline \multirow[t]{5}{*}{ Adults } & Dominant model & $2933 / 2670$ & 1.23 & $1.01-1.51(0.04)$ & 35.2 & 0.066 & -2.10 & 0.03 & -1.86 & 0.08 \\
\hline & Recessive model & $2933 / 2670$ & 1.21 & $1.04-1.40(0.01)$ & 46 & 0.01 & -0.91 & 0.36 & -0.71 & 0.48 \\
\hline & Allelic model & $2933 / 2670$ & 1.24 & $1.05-1.47(<0.001)$ & 63.8 & $<0.001$ & -0.97 & 0.33 & -1.45 & 0.16 \\
\hline & TT vs. CC & $2933 / 2670$ & 1.37 & $1.09-1.72(<0.001)$ & 5 & 0.39 & -1.01 & 0.47 & -1.77 & 0.19 \\
\hline & CT vs. CC & $2933 / 2670$ & 1.15 & $0.96-1.39(0.13)$ & 23 & 0.17 & -2.13 & 0.03 & -1.56 & 0.13 \\
\hline \multirow[t]{5}{*}{ Mixed } & Dominant model & $3585 / 3675$ & 0.92 & $0.65-1.32(0.65)$ & 83.6 & $<0.001$ & -0.09 & 0.92 & -1.05 & 0.31 \\
\hline & Recessive model & $3585 / 3675$ & 1.12 & $0.97-1.28(0.11)$ & 45.4 & 0.02 & -0.41 & 0.68 & 0.39 & 0.70 \\
\hline & Allelic model & $3585 / 3675$ & 1.03 & $0.85-1.24(0.78)$ & 76.3 & $<0.001$ & -0.72 & 0.47 & 0.02 & 0.98 \\
\hline & TT vs. CC & $3585 / 3675$ & 1.14 & $0.91-1.42(0.24)$ & 20.8 & 0.21 & -0.18 & 0.85 & -0.28 & 0.87 \\
\hline & CT vs. CC & $3585 / 3675$ & 0.87 & $0.59-1.28(0.48)$ & 84.9 & $<0.001$ & 0 & 1 & -1.11 & 0.28 \\
\hline \multicolumn{11}{|c|}{ Ethnicity-1 (Continent) } \\
\hline \multirow[t]{5}{*}{ Asia } & Dominant model & $5196 / 4936$ & 1.15 & $0.84-1.56(0.39)$ & 75.6 & $<0.001$ & -1.86 & 0.06 & -1.44 & 0.20 \\
\hline & Recessive model & $5196 / 4936$ & 1.16 & $1.06-1.28(<0.001)$ & 65 & $<0.001$ & -1.62 & 0.10 & -0.60 & 0.55 \\
\hline & Allelic model & $5196 / 4936$ & 1.17 & $1-1.37(0.04)$ & 76.7 & $<0.001$ & -1.72 & 0.08 & -1.04 & 0.30 \\
\hline & TT vs. CC & $5196 / 4936$ & 1.34 & $1.13-1.58(<0.001)$ & 42.7 & 0.01 & -1.48 & 0.13 & -1.15 & 0.40 \\
\hline & CT vs. CC & $5196 / 4936$ & 1 & $0.70-1.42(0.97)$ & 75.1 & $<0.001$ & -2 & 0.04 & -1.42 & 0.20 \\
\hline \multirow[t]{5}{*}{ Europe } & Dominant model & $1704 / 2347$ & 1.46 & $1.15-1.85(<0.001)$ & 56.9 & 0.01 & 0 & 1 & -0.70 & 0.49 \\
\hline & Recessive model & $1704 / 2347$ & 1.35 & $0.98-1.86(0.06)$ & 0 & 0.94 & -1.58 & 0.11 & -1.91 & 0.08 \\
\hline & Allelic model & $1704 / 2347$ & 1.34 & $1.12-1.61(<0.001)$ & 51 & 0.02 & -1.03 & 0.30 & -1.50 & 0.16 \\
\hline & $\pi$ vs. CC & $1704 / 2347$ & 1.53 & $1.10-2.14(0.01)$ & 0 & 0.80 & 0.16 & 0.87 & -0.87 & 0.40 \\
\hline & CT vs. CC & $1704 / 2347$ & 1.44 & $1.13-1.83(<0.001)$ & 55.6 & 0.01 & 0.78 & 0.43 & 0.33 & 0.74 \\
\hline \multirow[t]{5}{*}{ America } & Dominant model & $1991 / 1828$ & 1.22 & $0.95-1.58(0.11)$ & 54.5 & 0.01 & -1.33 & 0.27 & -2.05 & 0.07 \\
\hline & Recessive model & $1991 / 1828$ & 1.15 & $0.96-1.39(0.12)$ & 24.3 & 0.22 & -1.34 & 0.18 & 0.99 & 0.35 \\
\hline & Allelic model & $1991 / 1828$ & 1.19 & $0.99-1.44(0.06)$ & 64.8 & $<0.001$ & -0.98 & 0.32 & -0.48 & 0.64 \\
\hline & TT vs. CC & $1991 / 1828$ & 1.27 & $0.98-1.64(0.07)$ & 43.7 & 0.06 & -1.52 & 0.12 & -1.91 & 0.09 \\
\hline & CT vs. CC & $1991 / 1828$ & 1.18 & $0.94-1.48(0.15)$ & 39.3 & 0.09 & -1.52 & 0.12 & -1.94 & 0.08 \\
\hline \multicolumn{11}{|l|}{ Ethnicity-2 } \\
\hline \multirow[t]{5}{*}{ East-Asian } & Dominant model & 4246 / 3908 & 1.43 & $1.14-1.79(<0.001)$ & 26.3 & 0.14 & -1.08 & 0.28 & 1.53 & 0.29 \\
\hline & Recessive model & $4246 / 3908$ & 1.14 & $1.03-1.26(<0.001)$ & 66.6 & $<0.001$ & -1.02 & 0.27 & -1.51 & 0.36 \\
\hline & Allelic model & $4246 / 3908$ & 1.29 & $1.10-1.52(<0.001)$ & 72 & $<0.001$ & -1.79 & 0.58 & -3.10 & 0.06 \\
\hline & TT vs. CC & $4246 / 3908$ & 1.33 & $1.11-1.59(<0.001)$ & 41.8 & 0.02 & -1.27 & 0.29 & -1.39 & 0.31 \\
\hline & CT vs. CC & $4246 / 3908$ & 1.24 & $1.00-1.53(0.04)$ & 0 & 0.74 & -1.89 & 0.68 & -1.71 & 0.10 \\
\hline \multirow[t]{5}{*}{ Non-East-Asian } & Dominant model & $5333 / 5973$ & 1.10 & $0.90-1.36(0.35)$ & 77.4 & $<0.001$ & -0.80 & 0.42 & -1.18 & 0.35 \\
\hline & Recessive model & $5333 / 5973$ & 1.25 & $1.08-1.45(<0.001)$ & 21.9 & 0.14 & 0.59 & 0.55 & 0.73 & 0.47 \\
\hline & Allelic model & $5333 / 5973$ & 1.15 & $1-1.32(0.04)$ & 71.5 & $<0.001$ & -1.05 & 0.48 & -1.82 & 0.07 \\
\hline & Tा vs. CC & $5333 / 5973$ & 1.34 & $1.12-1.61(<0.001)$ & 24 & 0.11 & -0.37 & 0.70 & -1.04 & 0.30 \\
\hline & CT vs. CC & $5333 / 5973$ & 1.03 & $0.83-1.28(0.78)$ & 77.9 & $<0.001$ & -1.16 & 0.24 & -1.93 & 0.06 \\
\hline
\end{tabular}


Table 3 Main results of pooled ORs in meta-analysis of IL-4 gene polymorphisms in asthmatic patients (Continued)

\begin{tabular}{|c|c|c|c|c|c|c|c|c|c|c|}
\hline \multirow[t]{2}{*}{ Subgroup } & \multirow[b]{2}{*}{ Genetic model } & \multirow{2}{*}{$\begin{array}{l}\text { Sample size } \\
\text { Case/Control }\end{array}$} & \multicolumn{2}{|c|}{ Test of association } & \multicolumn{2}{|c|}{$\begin{array}{l}\text { Test of } \\
\text { heterogeneity }\end{array}$} & \multicolumn{2}{|c|}{$\begin{array}{l}\text { Test of publication } \\
\text { bias (Begg's test) }\end{array}$} & \multicolumn{2}{|c|}{$\begin{array}{l}\text { Test of publication } \\
\text { bias (Egger's test) }\end{array}$} \\
\hline & & & $\overline{\mathrm{OR}}$ & 95\% Cl ( $p$-value) & $\overline{I^{2}(\%)}$ & $P$ & $\bar{z}$ & $P$ & $\bar{t}$ & $P$ \\
\hline \multicolumn{11}{|l|}{ Ethnicity 3} \\
\hline \multirow[t]{5}{*}{ Caucasian } & Dominant model & $7360 / 7971$ & 1.30 & $1.12-1.51(<0.001)$ & 49.2 & $<0.001$ & -1.04 & 0.48 & -1.51 & 0.18 \\
\hline & Recessive model & $7360 / 7971$ & 1.16 & $1.06-1.27(<0.001)$ & 49.7 & $<0.001$ & -1.31 & 0.24 & -2.77 & 0.09 \\
\hline & Allelic model & $7360 / 7971$ & 1.25 & $1.12-1.39(<0.001)$ & 65 & $<0.001$ & 1.40 & 0.17 & -1.12 & 0.38 \\
\hline & TT vs. CC & $7360 / 7971$ & 1.34 & $1.16-1.56(<0.001)$ & 24.9 & 0.09 & -1.52 & 0.16 & -1.34 & 0.29 \\
\hline & CT vs. CC & $7360 / 7971$ & 1.22 & $1.05-1.42(<0.001)$ & 39.6 & $<0.001$ & -1.54 & 0.12 & -1.80 & 0.08 \\
\hline \multirow[t]{5}{*}{ Arab } & Dominant model & $316 / 284$ & 0.36 & $0.07-1.88(0.22)$ & 91.5 & $<0.001$ & 0.68 & 0.49 & -0.17 & 0.83 \\
\hline & Recessive model & $316 / 284$ & 1.53 & $0.27-1.48(0.09)$ & 87.4 & $<0.001$ & 0 & 1 & -1.67 & 0.19 \\
\hline & Allelic model & $316 / 284$ & 0.63 & $0.67-3.68(0.29)$ & 85.4 & $<0.001$ & 0.49 & 0.62 & -0.11 & 0.92 \\
\hline & Tा vs. CC & $316 / 284$ & 0.93 & $0.43-1.99(0.85)$ & 66.6 & 0.02 & 0.68 & 0.49 & 1.25 & 0.33 \\
\hline & CT vs. CC & $316 / 284$ & 0.29 & $0.05-1.84(0.19)$ & 92.3 & $<0.001$ & 0 & 1 & -0.71 & 0.55 \\
\hline \multirow[t]{5}{*}{ African-American } & Dominant model & $1903 / 1626$ & 1.34 & $1.07-1.67(0.01)$ & 35.3 & 0.13 & -1.67 & 0.09 & 1.97 & 0.27 \\
\hline & Recessive model & $1903 / 1626$ & 1.18 & $0.98-1.43(0.07)$ & 24.7 & 0.22 & 0.63 & 0.53 & 1.11 & 0.30 \\
\hline & Allelic model & $1903 / 1626$ & 1.25 & $1.04-1.50(0.01)$ & 58.9 & 0.01 & -1.46 & 0.14 & -0.81 & 0.44 \\
\hline & TT vs. CC & $1903 / 1626$ & 1.37 & $1.04-1.80(0.02)$ & 36.2 & 0.12 & -1.67 & 0.09 & -1.44 & 0.40 \\
\hline & CT vs. CC & $1903 / 1626$ & 1.30 & $1.06-1.58(0.01)$ & 13.9 & 0.31 & -1.67 & 0.09 & -1.46 & 0.41 \\
\hline
\end{tabular}

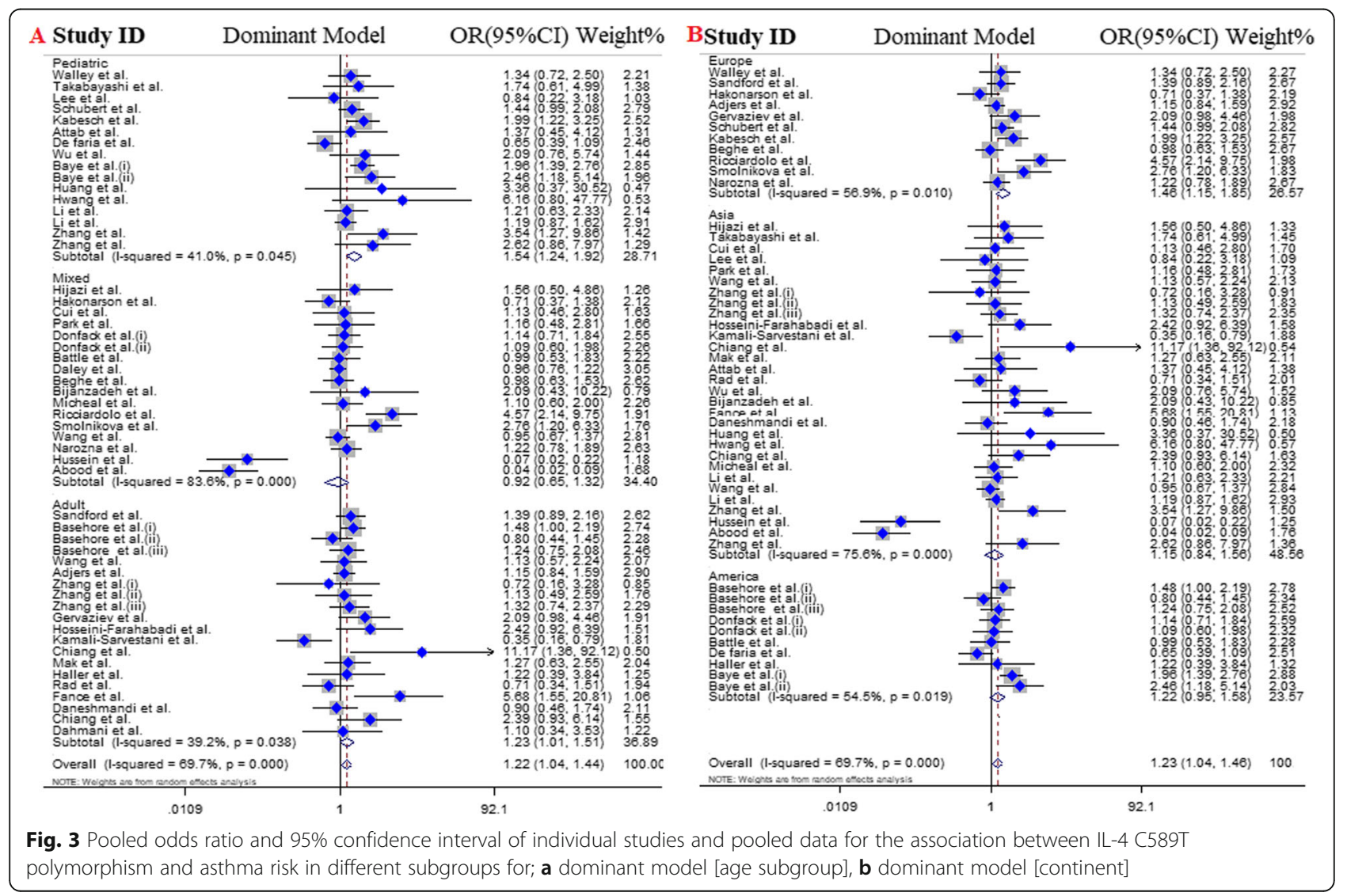




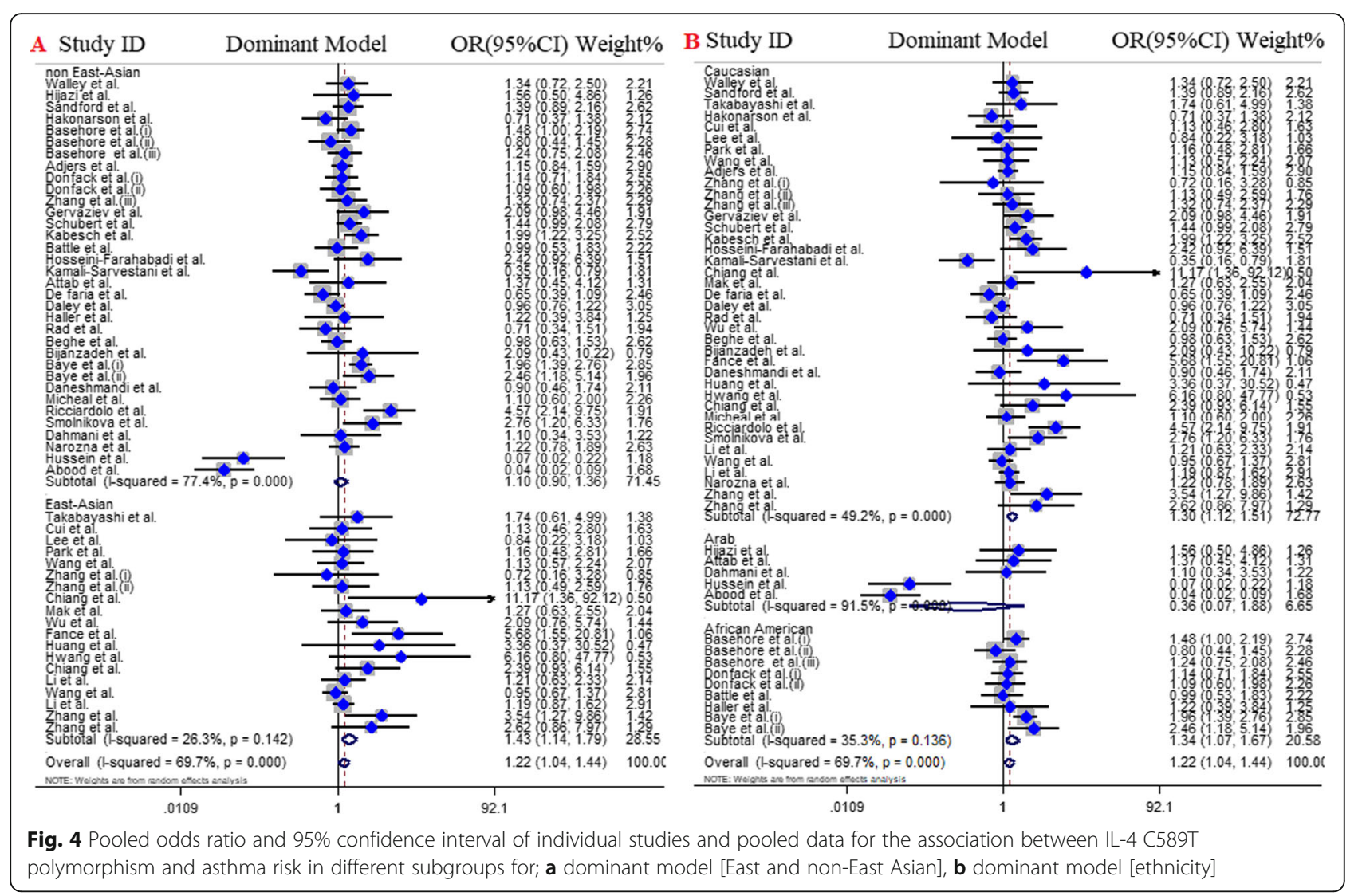

Table 4 Meta-regression analyses of potential source of heterogeneity

\begin{tabular}{|c|c|c|c|c|c|c|c|}
\hline \multirow[t]{2}{*}{ Heterogeneity Factors } & & \multirow[t]{2}{*}{ Coefficient } & \multirow[t]{2}{*}{ SE } & \multirow[t]{2}{*}{$\mathrm{T}$} & \multirow[t]{2}{*}{$P$-value } & \multicolumn{2}{|c|}{$95 \% \mathrm{Cl}$} \\
\hline & & & & & & UL & LL \\
\hline \multirow[t]{5}{*}{ Publication Year } & Dominant model & 0.035 & 0.041 & 0.85 & 0.40 & -0.048 & 1.119 \\
\hline & Recessive model & 0.140 & 0.036 & 3.81 & 0.07 & -0.066 & 0.213 \\
\hline & Allelic model & 0.035 & 0.022 & 1.58 & 0.11 & -0.009 & 0.080 \\
\hline & TT vs. CC & 0.123 & 0.064 & 1.91 & 0.06 & -0.006 & 0.254 \\
\hline & CT vs. CC & 0.020 & 0.035 & 0.58 & 0.56 & -0.050 & 0.090 \\
\hline \multirow[t]{5}{*}{ continent } & Dominant model & -0.238 & 0.265 & -0.90 & 0.37 & -0.772 & 0.294 \\
\hline & Recessive model & 0.022 & 0.274 & 0.08 & 0.93 & -0.530 & 0.574 \\
\hline & Allelic model & -0.116 & 0.146 & -0.79 & 0.43 & -0.410 & 0.177 \\
\hline & AA vs. CC & -0.096 & 0.435 & -0.22 & 0.82 & -0.973 & 0.780 \\
\hline & CA vs. CC & -0.265 & 0.209 & -1.27 & 0.21 & -0.685 & 0.154 \\
\hline \multirow[t]{5}{*}{ Genotyping methods } & Dominant model & -0.137 & 0.241 & -0.57 & 0.57 & -0.621 & 0.346 \\
\hline & Recessive model & 0.382 & 0.232 & 1.65 & 0.10 & -0.084 & 0.849 \\
\hline & Allelic model & 0.039 & 0.130 & 0.30 & 0.76 & -0.221 & 0.300 \\
\hline & TT vs. CC & 0.056 & 0.388 & 0.14 & 0.88 & -0.726 & 0.838 \\
\hline & CT vs. CC & -0.114 & 0.199 & -0.57 & 0.57 & -0.515 & 0.287 \\
\hline
\end{tabular}




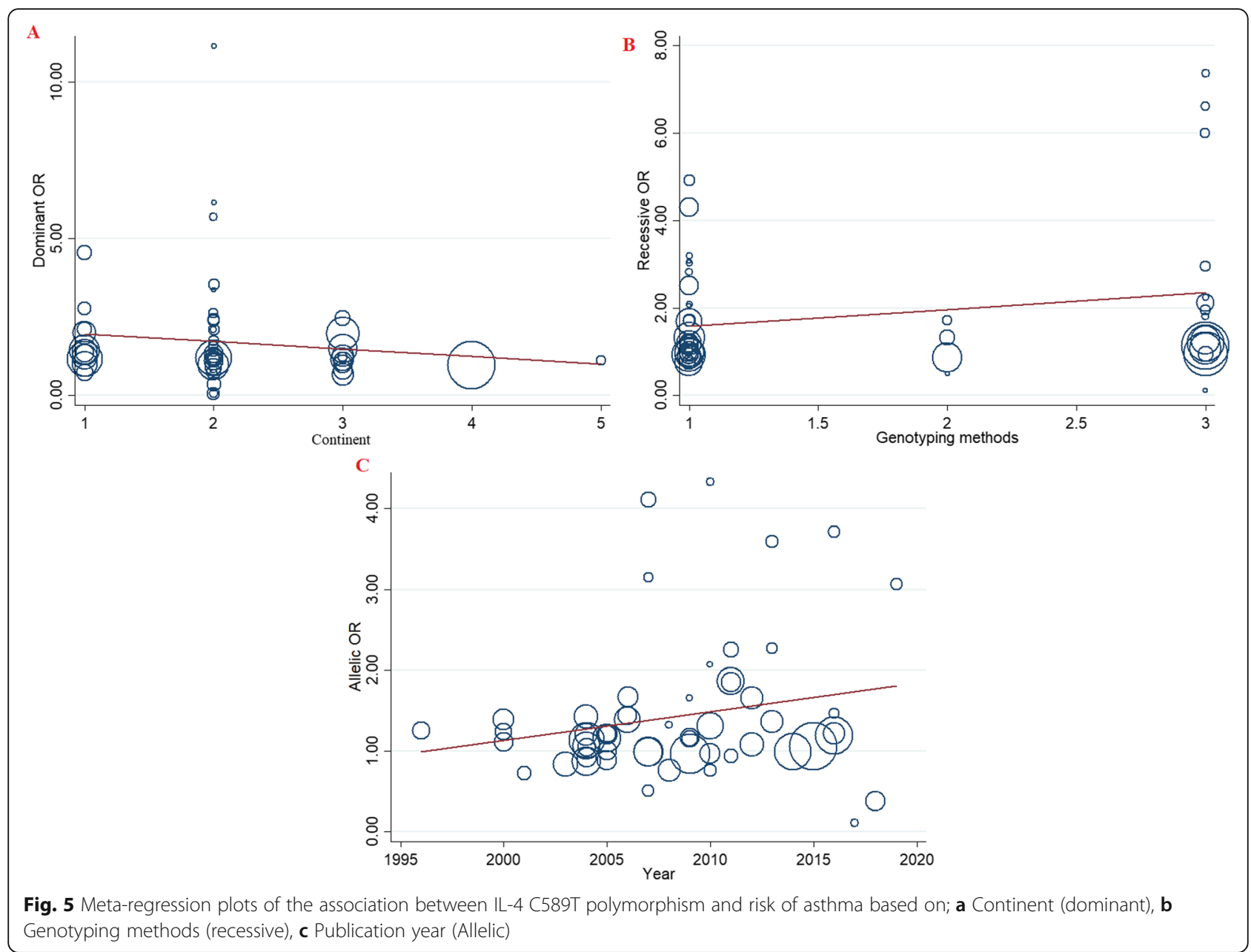

IL-13 promote the harmful inflammatory events in the airways. Studies have reported that local administration of IL-4 gene plasmids prior to antigen challenge could stimulate the airway hyperresponsiveness and accumulation of eosinophils in mice [77]. This phenotype of asthma is commonly referred to "eosinophilic" asthma. On the other side, "noneosinophilic" asthma is characterized by low frequency of eosinophils in the involved sites, but other inflammatory cells are dominant in the effector phase, such as neutrophils, mixed granulocyte inflammatory cells, or even little number of inflammatory cells, called paucigranulocytic inflammation. Th17 mediated IL-17 axis and lack of significant Th2/Th17 inflammation have been attributed to the noneosinophilic asthma [78]. Among the SNPs in the IL4 gene, the $-589 \mathrm{C} / \mathrm{T}$ ( $\mathrm{rs} 2243250$ ) polymorphism has been widely investigated in susceptibility to asthma. It has been shown that the $\mathrm{T}$ allele of this SNP leads to increased affinity of the binding of transcription factors in comparison to the $\mathrm{C}$ allele, leading to overexpression of IL4 mRNA [79, 80]. As a consequence, it is a biological justification that
IL4 gene $-589 \mathrm{C} / \mathrm{T}$ SNP impresses the IL-4 expression and, hence, could affect the asthma susceptibility.

Previously, three meta-analysis studies have attempted to disclose the association of IL4 gene $-589 \mathrm{C} / \mathrm{T}$ SNP with the risk of asthma. Wang et al. in 2012 indicated that the $\mathrm{T}$ allele of $I L 4$ gene $-589 \mathrm{C} / \mathrm{T}$ SNP increased the risk of asthma $(\mathrm{OR}=1.12)$. Basically, individuals carrying the $\mathrm{T}$ allele had a $24 \%$ increased risk of asthma in comparison to the CC homozygote model. Subgroup analysis revealed the association of this polymorphism in the Caucasians [81]. In addition, Nie et al. in 2013 included 40 studies involving 7345 cases and 7819 controls in their meta-analysis [18]. This meta-analysis indicated that $\mathrm{TT}$ vs. $\mathrm{CC}(\mathrm{OR}=1.40)$ and $\mathrm{CT}$ vs. $\mathrm{CC}(\mathrm{OR}=1.22)$ models were significantly associated with increased risk of asthma. In the subgroup analysis by ethnicity, significant associations were found among Asians and Caucasians, but not in the African-Americans. In addition, the subgroup analysis by atopic status revealed no significant association among atopic asthma patients and nonatopic asthma patients. On the other side, Zhang et al. 


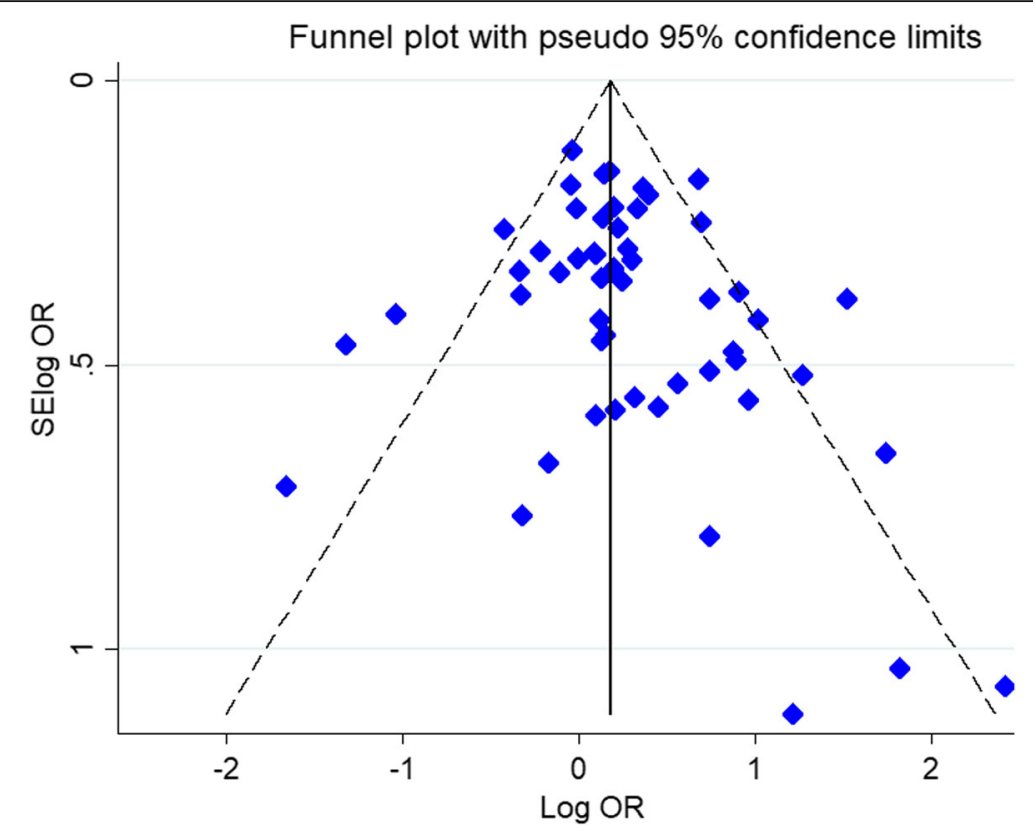

Fig. 6 Begg's funnel plot for publication bias test. Dominant model C598T. Each point represents a separate study for the indicated association

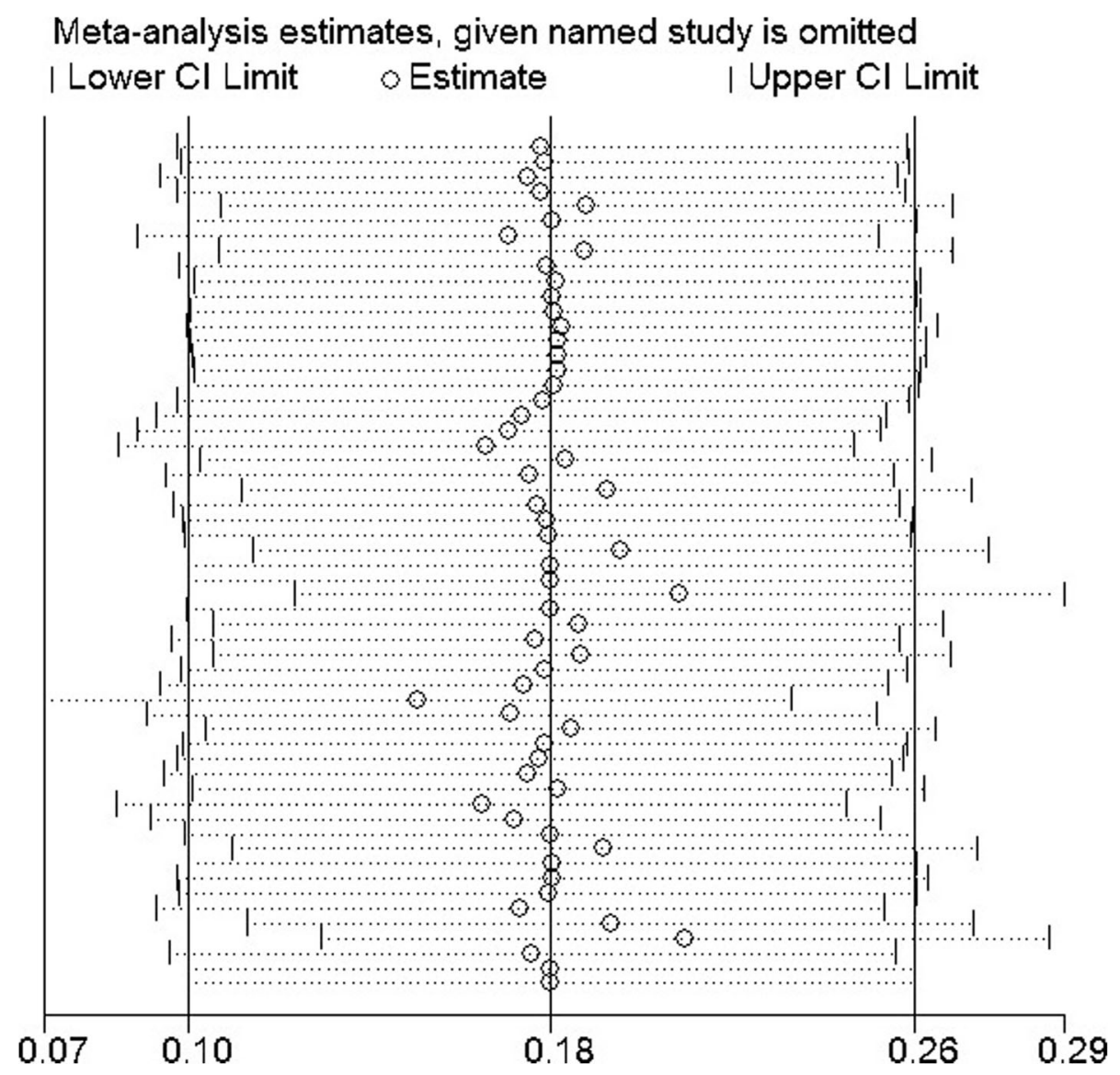

Fig. 7 Sensitivity analysis in present meta-analysis investigates the single nucleotide polymorphisms of IL-4 C589T contribute to risk for asthma 
[75] by evaluating pediatric asthma risk by evolving 17 case-control studies (15 publications) containing 3427 cases and 4247 controls revealed that IL4 -589C/T polymorphism was associated with increased risk of asthma in pediatrics. Furthermore, the subgroup analyses by ethnicity, indicated significant association in Caucasians and Asians.

Our analysis was performed on 55 case-control studies containing 9572 cases and 9881 controls. It was observed that $I L 4$ gene $-589 \mathrm{C} / \mathrm{T}$ polymorphism increased the risk of asthma across all genetic models, including dominant model $(\mathrm{OR}=1.22)$, recessive model $(\mathrm{OR}=$ 1.17), allelic model $(\mathrm{OR}=1.21)$, and TT vs. $\mathrm{CC}$ model $(\mathrm{OR}=1.34)$, but not the CT vs. TT model. Furthermore, subgroup analysis by age indicated that IL4 gene -589C/ $\mathrm{T}$ polymorphism was significantly associated with asthma risk in both pediatrics and adults. The subgroup analysis by ethnicity revealed significant association in Asian, American, and Europeans. Finally, subgroup analysis by East Asian and non-East Asian populations indicated significant associations.

This meta-analysis bears some limitations and caveats. First, the analysis was according to crude estimation of IL4 gene $-589 \mathrm{C} / \mathrm{T}$ polymorphism association with asthma susceptibility, regardless of the effect of confounding factors, like age, sex, environmental factors, and contribution of other genes in LD with IL4 gene. Second, we did not analyze other genes that could be contributing in understanding of cytokine involvement in the susceptibility to asthma.

\section{Conclusion}

All in all, here we carried out the most up-to-date analysis of the $I L 4$ gene $589 \mathrm{C} / \mathrm{T}$ polymorphism and asthma risk prior to September 2020. Our meta-analysis further confirmed some results of the previously performed meta-analysis, while rejected some of them. In a whole, IL4 gene $-589 \mathrm{C} / \mathrm{T}$ polymorphism increased the risk of asthma across all genetic models. Moreover, the subgroup analysis by age indicated that IL4 gene $-589 \mathrm{C} / \mathrm{T}$ polymorphism was significantly associated with asthma risk in both pediatrics and adults. Also, the subgroup analysis by ethnicity revealed significant association in Asian, American, and Europeans. Ultimately, subgroup analysis by East Asian and non-East Asian populations indicated significant associations.

\section{Abbreviations}

IL: Interleukin; Th: T helper; Cl: Confidence interval; OR: Odds ratio; SNP: Single-nucleotide polymorphism; PRISMA: Preferred Reporting Items for Systematic reviews and Meta-Analyses; NOS: Newcastle-Ottawa scale; HWE: Hardy-Weinberg equilibrium

Acknowledgements

Not applicable.

\section{Authors' contributions}

$\mathrm{BR}$ and $\mathrm{DI}$ originated the study, acquired data. AK, AMG, and AMF analyzed and interpreted the data. $\mathrm{MH}, \mathrm{MA}$, and $\mathrm{DI}$ prepared the original draft. BR, DI, and MJM critically revised the paper. SA and HM supervised the project. All authors read and approved the final manuscript.

\section{Funding}

Not applicable.

\section{Availability of data and materials}

All data that support the conclusions of this manuscript are included within the article.

Ethics approval and consent to participate

Not applicable.

Consent for publication

Not applicable.

\section{Competing interests}

The authors declare that they have no competing interests.

\section{Author details}

${ }^{1}$ Department of Health Education and Health Promotion, Faculty of Health, Tabriz University of Medical Sciences, Tabriz, Iran. ${ }^{2}$ Research Center for Advanced Technologies in Cardiovascular Medicine, Tehran Heart Center, Tehran University of Medical Sciences, Tehran, Iran. ${ }^{3}$ Legal medicine Research Center, Legal Medicine organization, Tehran, Iran. ${ }^{4}$ Department of Science, Islamshahr Branch, Islamic Azad University, Islamshahr, Tehran, Iran. ${ }^{5}$ Tyumen State Medical University, Tyumen, Russian Federation. ${ }^{6}$ Department of Immunology, School of Public Health, Tehran University of Medical Sciences, Tehran, Iran. ${ }^{7}$ Department of Hematology and Blood Banking, School of Medicine, Tarbiat Modares University, Tehran, Iran. ${ }^{8}$ Department of Hematology, Faculty of Allied Medicine, Bushehr University of Medical Sciences, Bushehr, Iran. ${ }^{9}$ Department of Immunology, School of Medicine, Tehran University of Medical Sciences, Tehran, Iran. ${ }^{10}$ Tuberculosis and Lung Diseases Research Center, Tabriz University of Medical sciences, Tabriz, Iran.

Received: 17 May 2020 Accepted: 8 October 2020

Published online: 21 October 2020

\section{References}

1. Makoui MH, Imani D, Motallebnezhad M, Azimi M, Razi B. Vitamin D receptor gene polymorphism and susceptibility to asthma: meta-analysis based on 17 case-control studies. Ann Allergy Asthma Immunol. 2020; 124(1):57-69.

2. Peters SP, Ferguson G, Deniz $Y$, Reisner C. Uncontrolled asthma: a review of the prevalence, disease burden and options for treatment. Respir Med. 2006;100(7):1139-51.

3. Subbarao P, Mandhane PJ, Sears MR. Asthma: epidemiology, etiology and risk factors. Cmaj. 2009;181(9):E181-90.

4. Sykes A, Johnston SL. Etiology of asthma exacerbations. J Allergy Clin Immunol. 2008;122(4):685-8.

5. Ober C, Yao TC. The genetics of asthma and allergic disease: a 21st century perspective. Immunol Rev. 2011;242(1):10-30.

6. Malerba G, Pignatti PF. A review of asthma genetics: gene expression studies and recent candidates. J Appl Genet. 2005;46(1):93-104.

7. Noutsios GT, Floros J. Childhood asthma: causes, risks, and protective factors; a role of innate immunity. Swiss Med Wkly. 2014;144(5152).

8. Hirschhorn JN, Lohmueller K, Byrne E, Hirschhorn K. A comprehensive review of genetic association studies. Genet Med. 2002;4(2):45-61.

9. Kendler KS, Chen X, Dick D, Maes H, Gillespie N, Neale MC, Riley B. Recent advances in the genetic epidemiology and molecular genetics of substance use disorders. Nat Neurosci. 2012;15(2):181.

10. Desai D, Brightling C. Cytokine and anti-cytokine therapy in asthma: ready for the clinic? Clin Exp Immunol. 2009;158(1):10-9.

11. Poulsen LK, Hummelshoj L. Triggers of IgE class switching and allergy development. Ann Med. 2007;39(6):440-56.

12. Bao K, Reinhardt RL. The differential expression of $\mathrm{IL}-4$ and $\mathrm{IL}-13$ and its impact on type-2 immunity. Cytokine. 2015;75(1):25-37. 
13. Rengarajan J, Szabo SJ, Glimcher LH. Transcriptional regulation of Th1/Th2 polarization. Immunol Today. 2000;21(10):479-83.

14. Weiss DL, Brown MA. Regulation of IL-4 production in mast cells: a paradigm for cell-type-specific gene expression. Immunol Rev. 2001;179(1): $35-47$.

15. Suzuki I, Hizawa N, Yamaguchi E, Kawakami Y. Association between a C+ 33T polymorphism in the IL-4 promoter region and total serum lgE levels. Clin Exp Allergy. 2000;30(12):1746-9.

16. Basehore MJ, Howard TD, Lange LA, Moore WC, Hawkins GA, Marshik PL, Harkins MS, Meyers DA, Bleecker ER. A comprehensive evaluation of IL4 variants in ethnically diverse populations: association of total serum lgE levels and asthma in white subjects. J Allergy Clin Immunol. 2004;114(1):807.

17. Hegab AE, Sakamoto T, Saitoh W, Massoud HH, Massoud HM, Hassanein KM, Sekizawa K. Polymorphisms of IL4, IL13, and ADRB2 genes in COPD. Chest. 2004;126(6):1832-9.

18. Nie W, Zhu Z, Pan X, Xiu Q. The interleukin-4- 589C/T polymorphism and the risk of asthma: a meta-analysis including 7345 cases and 7819 controls. Gene. 2013;520(1):22-9.

19. Rosenwasser L, Borish L. Promoter polymorphisms predisposing to the development of asthma and atopy. Clin Exp Allergy. 1998;28:13-5 discussion 26-18

20. Moher D, Liberati A, Tetzlaff J, Altman DG. Preferred reporting items for systematic reviews and meta-analyses: the PRISMA statement. Ann Intern Med. 2009;151(4):264-9.

21. Stang A. Critical evaluation of the Newcastle-Ottawa scale for the assessment of the quality of nonrandomized studies in meta-analyses. Eur J Epidemiol. 2010;25(9):603-5.

22. Mantel N, Haenszel W. Statistical aspects of the analysis of data from retrospective studies of disease. J Natl Cancer Inst. 1959;22(4):719-48.

23. DerSimonian R, Laird N. Meta-analysis in clinical trials. Control Clin Trials. 1986;7(3):177-88.

24. Begg CB, Mazumdar M. Operating characteristics of a rank correlation test for publication bias. Biometrics. 1994:1088-101.

25. Egger M, Smith GD, Schneider M, Minder C. Bias in meta-analysis detected by a simple, graphical test. Bmj. 1997:315(7109):629-34.

26. Donfack J, Schneider DH, Tan Z, Kurz T, Dubchak I, Frazer KA, Ober C. Variation in conserved non-coding sequences on chromosome $5 q$ and susceptibility to asthma and atopy. Respir Res. 2005;6(1):145.

27. Zhang W, Zhang X, Qiu D. Association of interleukin-4 and interleukin-4 receptor gene polymorphism and serum lgE levels in Chinese, Malayan and Hindoo. Zhonghua Jie He He Hu Xi Za Zhi. 2005;28:489-90.

28. Baye TM, Kovacic MB, Myers JMB, Martin LJ, Lindsey M, Patterson TL, He $H$, Ericksen MB, Gupta J, Tsoras AM. Differences in candidate gene association between European ancestry and African American asthmatic children. PLoS One. 2011;6(2).

29. Walley A, Cookson W. Investigation of an interleukin-4 promoter polymorphism for associations with asthma and atopy. J Med Genet. 1996; 33(8):689-92.

30. Hijazi Z, Haider M. Interleukin-4 gene promoter polymorphism [C5907] and asthma in Kuwaiti Arabs. Int Arch Allergy Immunol. 2000;122(3):190-4

31. Sandford AJ, Chagani T, Zhu S, Weir TD, Bai TR, Spinelli JJ, FitzGerald JM, Behbehani NA, Tan WC, Paré PD. Polymorphisms in the IL4, IL4RA, and FCERIB genes and asthma severity. J Allergy Clin Immunol. 2000;106(1):13540.

32. Takabayashi A, Ihara K, Sasaki Y, Suzuki Y, Nishima S, Izuhara K, Hamasaki N, Hara T. Childhood atopic asthma: positive association with a polymorphism of IL-4 receptor a gene but not with that of IL-4 promoter or fc $\varepsilon$ receptor I $\beta$ gene. Exp Clin Immunogenet. 2000;17(2):63-70.

33. Hákonarson H, Bjornsdottir US, Ostermann E, Arnason T, Adalsteinsdottir AE, Halapi E, Shkolny D, Kristjansson K, Gudnadottir SA, Frigge ML. Allelic frequencies and patterns of single-nucleotide polymorphisms in candidate genes for asthma and atopy in Iceland. Am J Respir Crit Care Med. 2001; 164(11):2036-44.

34. Cui T, Wu J, Pan S, Xie J. Polymorphisms in the IL-4 and IL-4R [a] genes and allergic asthma. Clin Chem Lab Med. 2003;41(7):888-92.

35. Lee SG, Kim BS, Kim JH, Lee SY, Choi SO, Shim JY, Hong TJ, Hong SJ. Genegene interaction between interleukin-4 and interleukin-4 receptor a in Korean children with asthma. Clin Exp Allergy. 2004;34(8):1202-8.
36. Park BL, Kim LH, Choi YH, Lee J-H, Rhim T, Lee YM, Uh S-T, Park H-S, Choi BW, Hong S-J. Interleukin 3 (IL3) polymorphisms associated with decreased risk of asthma and atopy. J Hum Genet. 2004;49(10):517-27.

37. Wang W, Halmurat W, Yilihamu S, Xiang Y, Ablikemu A. A study on the relationship between interleukin-4 promoter polymorphism and asthma in a Xinjiang Uyger population. Zhonghua Jie He He Hu Xi Za Zhi. 2004;27(7): 460-4.

38. Ådjers K, Karjalainen J, Pessi T, Eklund C, Hurme M. Epistatic effect of TLR4 and IL4 genes on the risk of asthma in females. Int Arch Allergy Immunol. 2005;138(3):251-6.

39. Gervaziev W, Kaznacheev V, Gervazieva V. Allelic polymorphisms in the interleukin-4 promoter regions and their association with bronchial asthma among the Russian population. Int Arch Allergy Immunol. 2006;141(3):25764.

40. Schubert K, Von Bonnsdorf H, Burke M, Ahlert I, Braun S, Berner R, Deichmann K, Heinzmann A. A comprehensive candidate gene study on bronchial asthma and juvenile idiopathic arthritis. Dis Markers. 2006;22(3): 127-32.

41. Kabesch M, Schedel M, Carr D, Woitsch B, Fritzsch C, Weiland SK, von Mutius E. IL-4/IL-13 pathway genetics strongly influence serum lgE levels and childhood asthma. J Allergy Clin Immunol. 2006;117(2):269-74.

42. Battle NC, Choudhry S, Tsai H-J, Eng C, Kumar G, Beckman KB, Naqvi M, Meade $\mathrm{K}$, Watson $\mathrm{HG}$, LeNoir M. Ethnicity-specific gene-gene interaction between IL-13 and IL-4Ra among African Americans with asthma. Am J Respir Crit Care Med. 2007;175(9):881-7.

43. Hosseini-Farahabadi S, Tavakkol-Afshari J, Rafatpanah H, Farid-Hosseini R, Daluei MK. Association between the polymorphisms of IL-4 gene promoter $(-590 \mathrm{C}>\mathrm{T}), \mathrm{IL}-13$ coding region (R130Q) and IL-16 gene promoter (-295T> C) and allergic asthma. Iran J Allergy Asthma Immunol. 2007;6:9-14.

44. Kamali-Sarvestani E, Ghayomi M, Nekoee A. Association of TNF-alpha-308 G/ a and IL-4-589 C/T gene promoter polymorphisms with asthma susceptibility in the south of Iran. J Investig Allergol Clin Immunol. 2007; 17(6):361.

45. Chiang $\mathrm{CH}$, Tang YC, Lin MW, Chung MY. Association between the IL-4 promoter polymorphisms and asthma or severity of hyperresponsiveness in Taiwanese. Respirology. 2007:12(1):42-8.

46. Mak JC, Ko FW, Chu CM, Leung HC, Chan HW, Cheung AH, Ip MS, ChanYeung M. Polymorphisms in the IL-4, IL-4 receptor a chain, TNF-a, and lymphotoxin-a genes and risk of asthma in Hong Kong Chinese adults. Int Arch Allergy Immunol. 2007;144(2):114-22.

47. Attab KA, Al-Qaoud KM, Al-Bataieneh K, Ajlouni MJ. Association of SNP in the IL-4, IL-18 and eotaxin genes with asthma in a Jordanian population. Int J Integrative Biol. 2008:4(2):86.

48. De Faria IC, De Faria EJ, Toro AA, Ribeiro JD, Bertuzzo CS. Association of TGF- $\beta 1$, CD14, IL-4, IL-4R and ADAM33 gene polymorphisms with asthma severity in children and adolescents. J Pediatr. 2008;84:203-10.

49. Jiang P, Liu J, Xue-Bo Y, Rong-Yu L. Several interleukin-4 and interleukin-13 gene single nucleotide polymorphisms among Chinese asthmatic patients. In: Allergy and asthma proceedings: OceanSide Publications; 2009. p. 413.

50. Amirzargar A, Movahedi M, Rezaei N, Moradi B, Dorkhosh S, Mahloji M, Mandaviani S. 2 polymorphisms in IL4 and IL4RA confer susceptibility to asthma. J Investig Allergol Clin Immunol. 2009;19(6):433.

51. Daley D, Lemire M, Akhabir L, Chan-Yeung M, He JQ, McDonald T, Sandford A, Stefanowicz D, Tripp B, Zamar D. Analyses of associations with asthma in four asthma population samples from Canada and Australia. Hum Genet. 2009;125(4):445-59.

52. Haller G, Torgerson DG, Ober C, Thompson EE. Sequencing the IL4 locus in African Americans implicates rare noncoding variants in asthma susceptibility. J Allergy Clin Immunol. 2009;124(6):1204-1209.e1209.

53. Abdi Rl, Bagheri M, Rahimirad MH, Moradi Z. IFN- $\gamma+874$ and IL-4-590 polymorphisms and asthma susceptibility in north west of Iran; 2010.

54. Wu X, Li Y, Chen Q, Chen F, Cai P, Wang L, Hu L. Association and genegene interactions of eight common single-nucleotide polymorphisms with pediatric asthma in middle China. J Asthma. 2010;47(3):238-44.

55. Beghé B, Hall I, Parker S, Moffatt M, Wardlaw A, Connolly M, Fabbri L, Ruse C, Sayers I. Polymorphisms in IL13 pathway genes in asthma and chronic obstructive pulmonary disease. Allergy. 2010;65(4):474-81.

56. Bijanzadeh M, Ramachandra NB, Mahesh P, Mysore RS, Kumar P, Manjunath B, Jayaraj B. Association of IL-4 and ADAM33 gene polymorphisms with asthma in an Indian population. Lung. 2010;188(5):415-22. 
57. Fan C, Liu Y, Ma Y, Zhang W. Susceptibility gene polymorphism and bronchial asthma. Prog Modn Biomed. 2010;10(17):3264-7.

58. Daneshmandi S, Pourfathollah AA, Pourpak Z, Heidarnazhad H, Kalvanagh PA. Cytokine gene polymorphism and asthma susceptibility, progress and control level. Mol Biol Rep. 2012;39(2):1845-53.

59. Huang $\mathrm{H}-\mathrm{R}$, Zhong $\mathrm{Y}-\mathrm{Q}, \mathrm{W}$ U J-F. The association between IFN- $\gamma$ and IL-4 genetic polymorphisms and childhood susceptibility to bronchial asthma. Gene. 2012;494(1):96-101.

60. Hwang B-F, Liu I-P, Huang T-P. Gene-environment interaction between interleukin-4 promoter and molds in childhood asthma. Ann Epidemiol. 2012:22(4):250-6.

61. Chiang $\mathrm{C}-\mathrm{H}$, Lin $\mathrm{M}-\mathrm{W}$, Chung $\mathrm{M}-\mathrm{Y}$, Yang $\mathrm{U}-\mathrm{C}$. The association between the IL-4, ADRß2 and ADAM 33 gene polymorphisms and asthma in the Taiwanese population. J Chin Med Assoc. 2012;75(12):635-43.

62. Micheal S, Minhas K, Ishaque M, Ahmed F, Ahmed A. IL4 gene polymorphisms and their association with atopic asthma and allergic rhinitis in Pakistani patients; 2013.

63. Ricciardolo FLM, Sorbello V, Silvestri M, Giacomelli M, Debenedetti V, Malerba M, Ciprandi G, Rossi G, Rossi A, Bontempelli M. TNF-a, IL-4Ra and IL-4 polymorphisms in mild to severe asthma from Italian Caucasians. Int J Immunopathol Pharmacol. 2013;26(1):75-84.

64. Smolnikova MV, Smirnova SV, Freidin MB, Tyutina OS. Immunological parameters and gene polymorphisms (C-590T IL4, C-597A IL 10) in severe bronchial asthma in children from the Krasnoyarsk region, West Siberia. Int J Circumpolar Health. 2013;72(1):21159.

65. Li J, Lin L-H, Wang J, Peng X, Dai H-R, Xiao H, Li F, Wang Y-P, Yang Z-J, Li L. Interleukin-4 and interleukin-13 pathway genetics affect disease susceptibility, serum immunoglobulin E levels, and gene expression in asthma. Ann Allergy Asthma Immunol. 2014;113(2):173-179.e171.

66. Wang R-S, Jin H-X, Shang S-Q, Liu X-Y, Chen S-J, Jin Z-B. Relación entre la expresión de IL-2 e IL-4 y sus polimorfismos y los riesgos de padecer infección por Mycoplasma pneumoniae y asma en niños. Arch Bronconeumol. 2015;51(11):571-8.

67. Dahmani DI, Sifi K, Salem I, Chakir J, Hanachi S, Bachtarzi MZ, Rouabah L Abadi N, Bougrida M, Rouabhia M. The C-589T IL-4 single nucleotide polymorphism as a genetic factor for atopic asthma, eczema and allergic rhinitis in an eastern Algerian population. Int J Pharm Sci Rev Res. 2016; 37(1):213-23.

68. Li L, Li Y, Zeng X, Li J, Du X. Role of interleukin-4 genetic polymorphisms and environmental factors in the risk of asthma in children. Genet Mol Res. 2016;15(4):534-43.

69. Narożna B, Hoffmann A, Sobkowiak P, Schoneich N, Bręborowicz A, Szczepankiewicz A. Polymorphisms in the interleukin 4, interleukin 4 receptor and interleukin 13 genes and allergic phenotype: a case control study. Adv Med Sci. 2016;61(1):40-5.

70. Hussein IA, Jaber SH. Genotyping of IL-4- 590 (C> T) gene in Iraqi asthma patients. Dis Markers. 2017;2017.

71. Abood SH, Mohanad A-E. Study of the correlation between total immunoglobulin-E levels and inter-leukin-4 polymorphism in asthmatic children. Int J Res Pharm Sci. 2018;9(4):1515-23.

72. Zhang J-H, Zhang M, Wang Y-N, Zhang X-Y. Correlation between IL-4 and IL-13 gene polymorphisms and asthma in Uygur children in Xinjiang. Exp Ther Med. 2019;17(2):1374-82.

73. Zhang J, Zhou G, Wei T, Chang Z. Association between the interleukin 4 gene-590C> T promoter polymorphism and asthma in Xinjiang Uighur children. Genet Mol Res. 2016;15(3).

74. Lilly CM. Diversity of asthma: evolving concepts of pathophysiology and lessons from genetics. J Allergy Clin Immunol. 2005;115(4):S526-31.

75. Zhang S, Li Y, Liu Y. Interleukin-4-589C/T polymorphism is associated with increased pediatric asthma risk: a meta-analysis. Inflammation. 2015;38(3): 1207-12.

76. Carpaij OA, Burgess JK, Kerstjens HA, Nawijn MC, van den Berge M. A review on the pathophysiology of asthma remission. Pharmacol Ther. 2019;201:824.

77. Fu C-L, Ye Y-L, Lee $Y-L$, Chiang B-L. Effects of overexpression of IL-10, IL-12, TGF- $\beta$ and IL-4 on allergen induced change in bronchial responsiveness. Respir Res. 2006;7(1):72.

78. Carr TF, Zeki AA, Kraft M. Eosinophilic and Noneosinophilic asthma. Am J Respir Crit Care Med. 2018;197(1):22-37.
79. Akkad D, Arning L, Ibrahim S, Epplen J. Sex specifically associated promoter polymorphism in multiple sclerosis affects interleukin 4 expression levels. Genes Immun. 2007;8(8):703-6.

80. Rosenwasser $\sqcup$, Borish L. Genetics of atopy and asthma: the rationale behind promoter-based candidate gene studies (IL-4 and IL-10). Am J Respir Crit Care Med. 1997;156(4):S152-5.

81. Wang Z-d, Lian D, Shen J-L, Sun R, Xu W, Xin Z, Lei L, Jin L-H. Association between the interleukin-4, interleukin-13 polymorphisms and asthma: a meta-analysis. Mol Biol Rep. 2013;40(2):1365-76.

\section{Publisher's Note}

Springer Nature remains neutral with regard to jurisdictional claims in published maps and institutional affiliations.
Ready to submit your research? Choose BMC and benefit from:

- fast, convenient online submission

- thorough peer review by experienced researchers in your field

- rapid publication on acceptance

- support for research data, including large and complex data types

- gold Open Access which fosters wider collaboration and increased citations

- maximum visibility for your research: over $100 \mathrm{M}$ website views per year

At BMC, research is always in progress.

Learn more biomedcentral.com/submissions 